Portland State University

PDXScholar

Spring 5-20-2013

\title{
Student Employment in Student Affairs Units: Characteristics of Educationally Purposeful Environments
}

Shannon Timm Watson

Portland State University

Follow this and additional works at: https://pdxscholar.library.pdx.edu/open_access_etds

Part of the Educational Leadership Commons, and the Higher Education Administration Commons Let us know how access to this document benefits you.

\section{Recommended Citation}

Watson, Shannon Timm, "Student Employment in Student Affairs Units: Characteristics of Educationally Purposeful Environments" (2013). Dissertations and Theses. Paper 1053.

https://doi.org/10.15760/etd.1053

This Dissertation is brought to you for free and open access. It has been accepted for inclusion in Dissertations and Theses by an authorized administrator of PDXScholar. Please contact us if we can make this document more accessible: pdxscholar@pdx.edu. 
Student Employment in Student Affairs Units: Characteristics of Educationally

Purposeful Environments

by

Shannon Timm Watson

A dissertation submitted in partial fulfillment of the requirements for the degree of

Doctor of Education

in

Educational Leadership: Postsecondary Education

Dissertation Committee:

Karen J. Haley, Chair

Christine M. Cress

Jean M. Henscheid

Martha Balshem

Portland State University

2013 


\begin{abstract}
Approximately $80 \%$ of undergraduate students work during the course of their undergraduate studies. Ideally, student's on-campus employment would contribute to his or her learning and development. However, because student employment is typically approached as the fulfillment of job tasks rather than student development, higher education institutions miss critical opportunities for supporting student academic and social integration. This study reframes on-campus student employment as a developmental effort. Data in this qualitative study indicate that on-campus employment can offer opportunities for student development and academic and social integration, and that it can positively influence students' sense of mattering and overall satisfaction with their college experience. It highlights the importance of supervision in student employment and informs our understanding of the ways different types of jobs can influence students' experiences. Given that students with fewer economic resources often come from educationally disadvantaged backgrounds and are potentially more at-risk for not completing their studies, colleges and universities should reconfigure on-campus jobs as opportunities for both employment and academic success.
\end{abstract}




\section{Acknowledgements}

This project would not have been possible without the dedicated guidance of my advisor, Dr Karen Haley. Her patience, critical feedback and sense of humor made this a great learning experience. I also want to thank my colleagues and my supervisor in Student Activities and Leadership Programs at Portland State for their support and patience throughout this project. I'm grateful for the students I've been fortunate to supervise and advise through my doctoral education as well: your insight into your own growth trajectory has been enlightening and sustaining. I would like to thank members of my educational cohort for their support, and the participants in this study for their candor and their time. Finally, many thanks to my spouse and my family. Your support is always spot-on, and I appreciate your listening, critical ear, all the cups of tea you made me, and your patience for hearing about this project every day for three years. 


\section{Table of Contents}

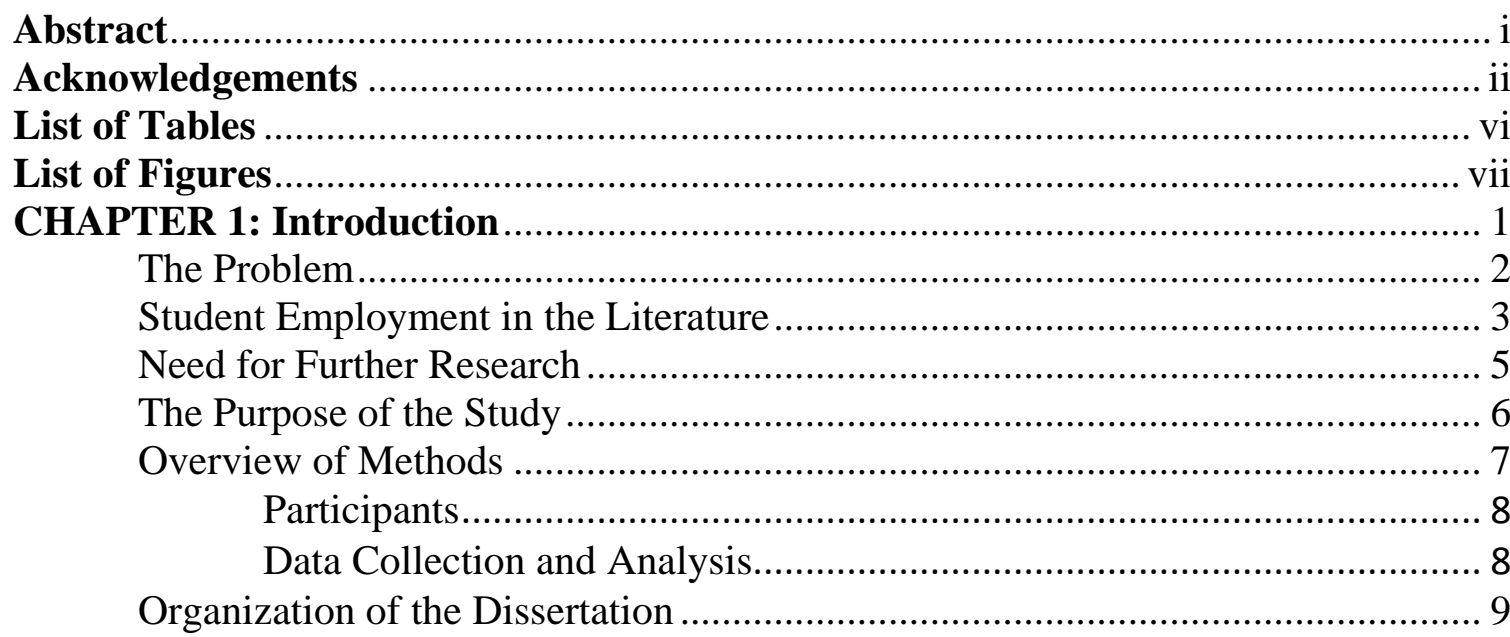

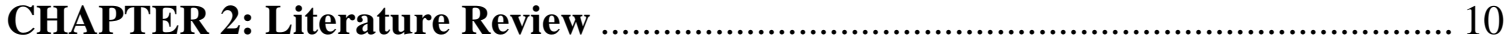

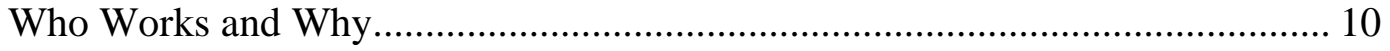

Conceptual Framework ............................................................................... 14

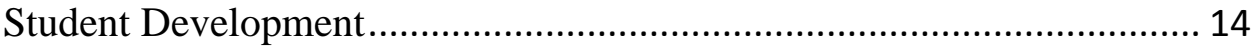

Student Employment...................................................................... 17

Academic and Social Integration ..................................................... 19

Student Satisfaction ................................................................. 25

Employment Factors Related to Retention and Persistence .............................. 26

Gaps in the Research.................................................................................. 27

Study Purpose and Potential Contribution ......................................................... 29

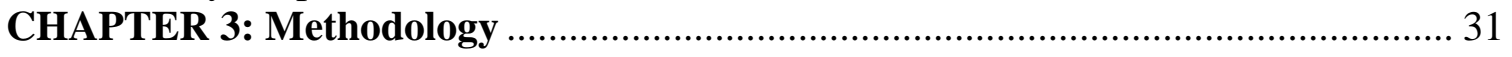

Focus of the Study and Research Questions ................................................. 31

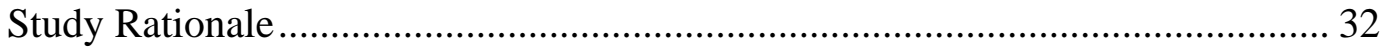

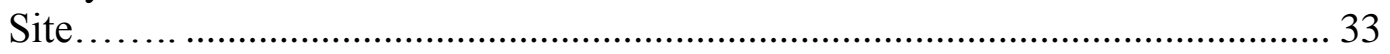

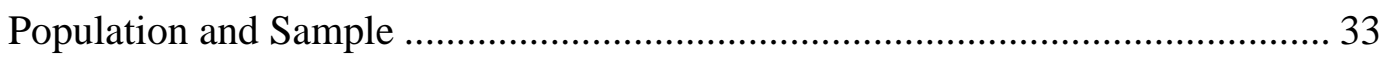

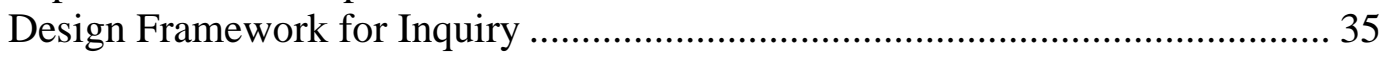

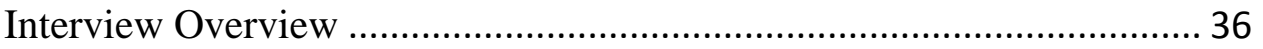

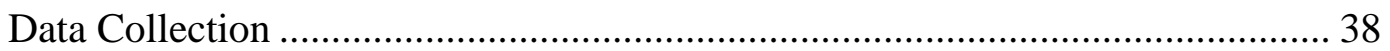

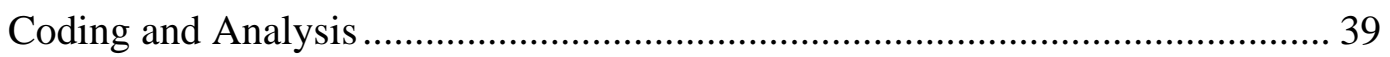

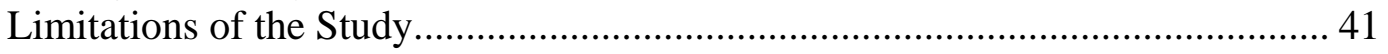

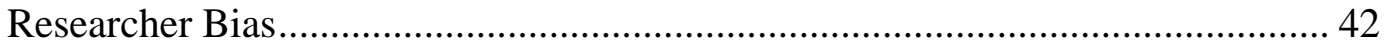

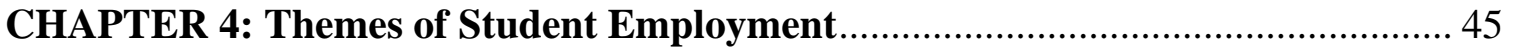

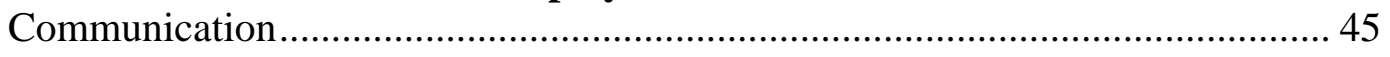

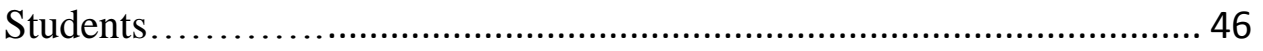

Faculty, Staff, and Administrators .................................................. 52

External Entities....................................................................... 56

Summary of the Communication Theme .............................................. 57 


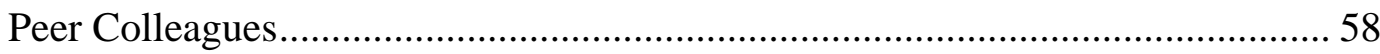

Regular Work Responsibilities ............................................................. 59

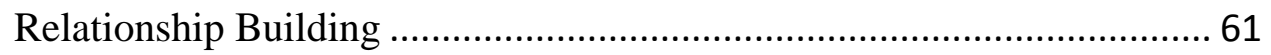

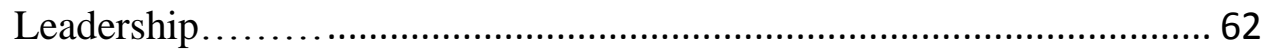

Summary of the Peer Colleagues Theme ................................................. 64

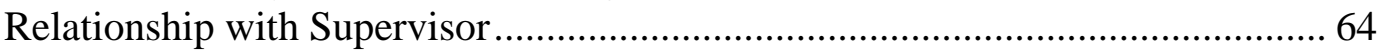

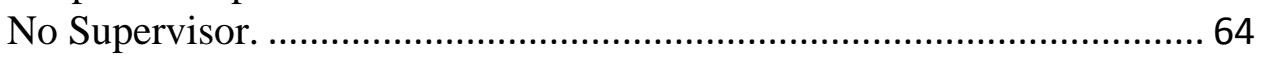

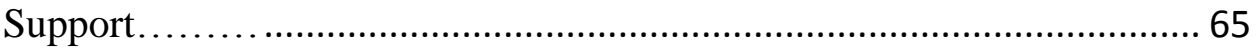

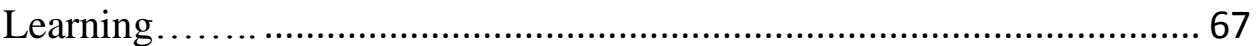

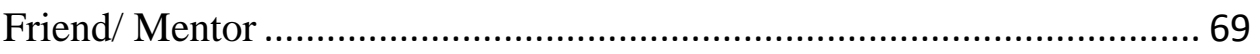

Summary of Relationship with Supervisor Theme .................................. 71

Academic Connection ................................................................................... 72

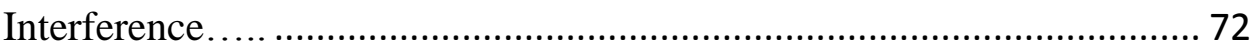

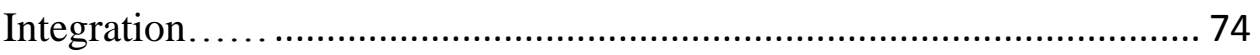

Summary of Academics Theme .......................................................... 77

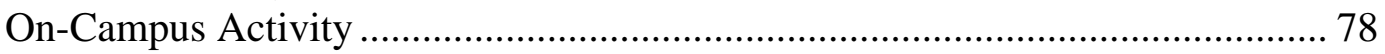

Attendance at Campus Events ............................................................. 78

Utilization of Campus Resources.......................................................... 81

Summary of On-Campus Activity Theme …………………………..... 82

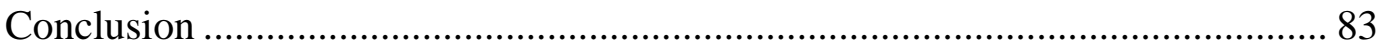

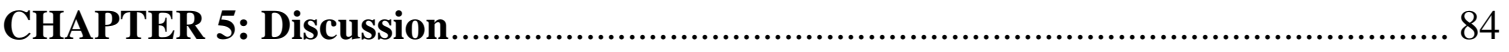

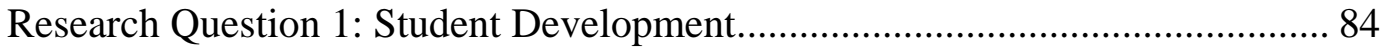

Developing Competence ........................................................................ 85

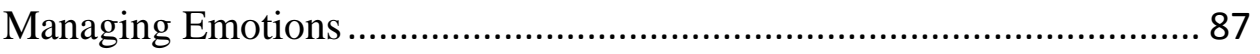

Moving Through Autonomy Toward Interdependence ............................ 88

Developing Mature Interpersonal Relationships ……………………...... 89

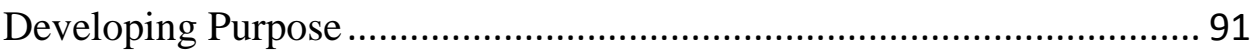

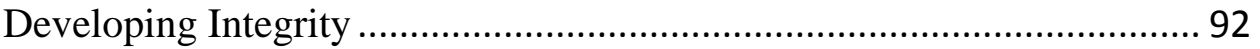

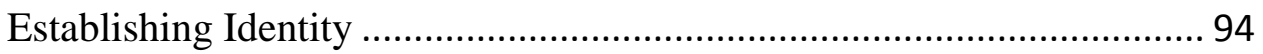

Conclusion to Research Question 1 ................................................................. 97

Research Question 2: Academic and Social Integration..................................... 100

Academic and Social Integration ....................................................... 101

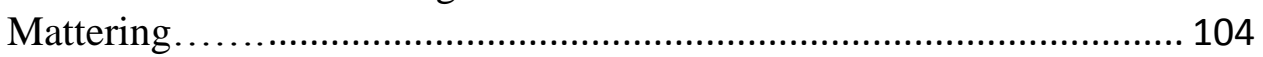

Conclusion of Research Question 2 ………………………............................. 111

Research Question 3: Satisfaction ................................................................. 114

Social Integration with Campus........................................................... 115

Connections between Work and Academics........................................ 116

Conclusion to Research Question 3 ............................................................... 120

Student Employment Reconsidered ............................................................ 122

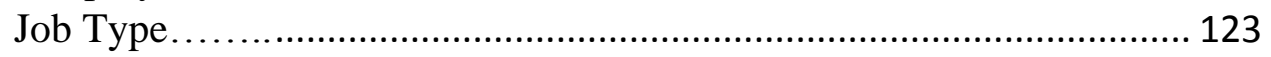

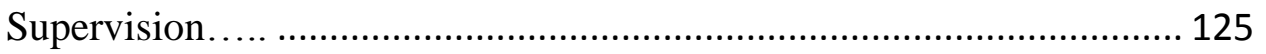


Conclusion to Student Employment Reconsidered........................................ 126

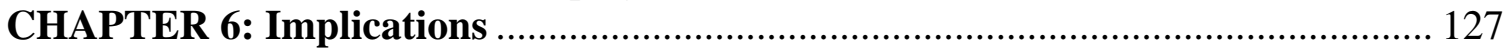

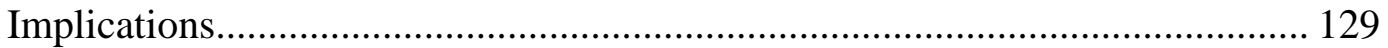

Implications for Research .............................................................. 129

Implications for Practice of Student Affairs Professionals................... 132

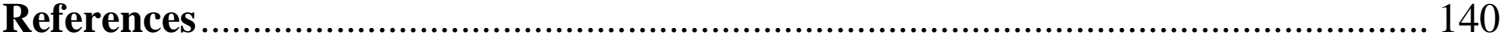

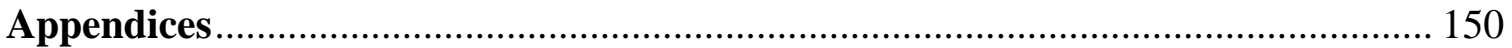

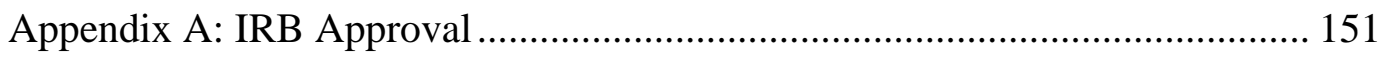

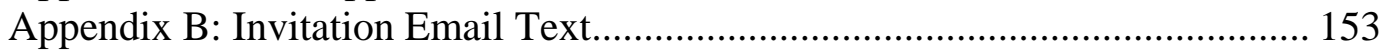

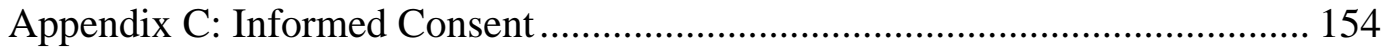

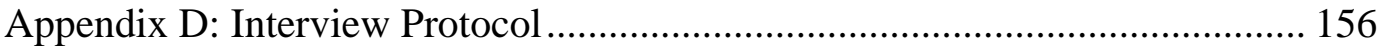

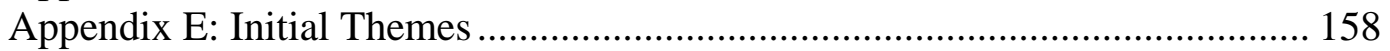




\section{List of Tables}

Table 1: Study participants by position type..................................... 35 


\section{List of Figures}

Figure 1: Conceptual model ....................................................... 14 


\section{CHAPTER 1: Introduction}

Work is a basic reality of life for most undergraduate students in the United States. The number of students who work while attending college has grown steadily, doubling in the years between 1961 and 2000 (Tuttle, McKinney, \& Rago, 2005). In 2008, the National Center for Education Statistics (Staklis, Chen, \& NCES, 2010) reported that nearly $80 \%$ of students pursuing an undergraduate education worked while attending school.

While students work for a variety of reasons, financial need is the most common reason students work (Lundberg, 2004). Unsurprisingly, students with the greatest financial need work the most hours to put themselves through school (Tuttle et al., 2007). Because of historical lack of equitable access to education and resources, students of color tend to have greater financial need than their White classmates (Pascarella \& Terenzini, 2005; Kantrowitz, 2011). Similarly, first generation students also tend to have more limited financial resources than their classmates who have parents that have attained a higher degree. All three of these populations, students from low SES (Pike \& Kuh, 2005), students of color (Pascarella \& Terenzini, 2005) and first generation students (Bozick, 2007) have been shown to have higher attrition rates than their peers.

Ideally, all of a student's on-campus experiences would contribute to his or her learning and development. However, because student employment is typically approached as an employment setting and not an environment to encourage student 
development and engagement, opportunities are missed for student growth and development in programs most often used by students with limited resources.

\section{The Problem}

While there is evidence that student employment can act as both a benefit and a detriment to students' academic success, research on the effect of on-campus employment on student outcomes has not yet resolved how the relationship happens, nor does it even agree on results (Pusser, 2010). It is very common for students to work during their academic experience; therefore, this is an important area of study because of the large number of students affected. In 2008, the National Center for Education Statistics reported that nationwide, nearly $80 \%$ of students pursuing an undergraduate education worked while attending school (Staklis et. al, 2010). Many of those students work on campus. Failure to consider the impact of a phenomenon that affects such a large number of students and to adjust on-campus employment environments accordingly constitutes a wasted opportunity for enhancing students' personal growth and professional development with minimal cost to the university.

According to the Center for the Study of College Student Retention (2012), understanding persistence and retention is important. Identifying factors related to students returning from one term to the next and persisting to graduation can help an institution identify areas to improve their effectiveness. Studying student employment in the context of student development can be important to understanding and developing 
mitigating factors related to student attrition. (McCubbin, 2003), therefore, colleges and universities must determine effective strategies for fostering persistence.

\section{Student Employment in the Literature}

Researchers have explored student employment's relationship with student success. Although the research on the effect student employment has on student success will be revealed in the next chapter to be mixed, studies are consistent in showing a curvilinear relationship between numbers of hours students work on campus while taking classes and measures of academic success, including critical thinking (Cheng, 2004), academic progress (Furr \& Ellig, 2000), and grades (Pascarella \& Terenzini, 2005). Students who work a reasonable number of hours (varying from 10 to 20 per week) on campus also showed higher rates of persistence relative to students who do not work at all, as well as to those working a large amount of hours on campus (over 20 per week) (Horn et al., 1998; Kuh,1995; and Kulm \& Cramer, 2006). These results suggest that there are dimensions of on-campus student employment that have positive impacts on student retention.

Another interesting factor found in the literature is that so far, the research has only begun to examine intrinsic differences in the employment positions themselves (Derous \& Ryan, 2008; Cheng, 2004; and Pike, Kuh, \& Massa McKinley, 2010). Researchers have largely focused on student employment in broad strokes, comparing oncampus versus off-campus employment and looking at outcomes through the lens of numbers of hours worked (Wolf-Wendel, Ward \& Kinzie, 2009). In addition, Federal 
Work Study positions were almost always the source of quantitative data for on-campus positions.

Student affairs researchers have produced a rich body of literature defining aspects of the student experience that are correlated with persistence to degree, clearly an important measure of student success. The work of Astin (1993) and Tinto (1993) offer foundations upon which this body of work is predicated (Pascarella \& Terenzini, 2005). While the scope of student success is broad, in the construction of this study, the focus centered on academic and social integration, along with student satisfaction, all of which have been shown to serve as proxies for retention and persistence. Persistence, retention and ultimately graduation are important: "educational attainment may not be an educational outcome in and of itself, but education clearly has a powerful influence on a student's future occupational, social, and economic status as well as on other factors that affect quality of life" (Pascarella \& Terenzini, 2005, p. 436).

Studies on the impact of working on student outcomes in college have been rooted in theories describing why students do or do not persist in college, including Astin's Theory of Involvement (1993) and Tinto's Theory of Student Departure (1993). Astin and Tinto both stated in these theories that any activity that took students' attention away from meaningful engagement in academic efforts must have a negative effect on their academic success. Particularly at the time these theories were being developed, the opinion of these scholars and other researchers was that working redirects students' efforts away from engagement in efforts related to academics, "Therefore, employment 
likely reduces the quality of educational experiences for at least some portion of students" (Perna, 2006, p. 3).

Two other theories are notable in the research of the influence of student employment on students' overall development and experience in college. Chickering and Reisser's (1993) work on the seven vectors of student development and the idea of Mattering championed by Rosenberg and McCullough (1981) and Schlossberg, Lynch, and Chickering (1989) will also be explored in the next chapter.

As will be explored in Chapter 2, researchers generally agree that there is a relationship between hours worked on campus and positive student outcomes, and that the relationship is nonlinear. Students who work on campus, for fewer than 15 to 20 hours per week have realized a benefit in persistence and retention over their nonworking peers (Pike et. al, 2008; Kulm \& Cramer, 2006; Pascarella \& Terenzini, 2005; and Kuh, 1995), as well as to their peers working excessive amounts on campus, or working off campus. Put another way, working a moderate number of hours is linked to additional benefits that are not realized to the same degree by students working not at all or an excessive amount. This indicates that there are benefits associated with on-campus employment.

\section{Need for Further Research}

Scholars have made calls for additional research ranging from the need to understand implications of employment for student learning and other educational outcomes and how employers can promote academic success for working students 
(Lewis, 2010; Perna, 2010; Lundberg 2004), to a call to examine different outcomes that may correlate with different types of student work (Lundberg, 2004). Scholars all agree on the need for further study of this phenomenon.

The need to work during college affects a large number of students in the United States, and yet "no theoretical models have been developed to explain the relationship between employment and student outcomes" (Derous \& Ryan, 2008 p. 63). Riggert et al. (2006), recommend identifying a theoretical model to approach the study of student employment, and they also suggest clarifying and standardizing both variables and the terminology used in research processes in this area.

Existing research suggests that there may be a benefit to student success and retention that can be realized through on-campus employment for undergraduates, but research has not yet identified what about employment may help or hinder measures of student success, including student development, academic and social integration or satisfaction. "There is no debate as to the importance of clearly understanding the impact of a situation that affects $80 \%$ of the nation's undergraduates" (Riggert, et al., $2006 \mathrm{p}$. 88), therefore, understanding the way in which working affects college students will help scholars and practitioners improve their practice.

\section{The Purpose of the Study}

There is much we do not yet know in the area of on-campus employment and how it affects students' overall experience with college life. The purpose of this study is to examine on-campus employment from the perspective of student workers who persisted 
in their jobs and in their academics after a year of on-campus employment. This study has three research questions at its core:

1. How does on-campus employment facilitate and/ or hinder students' development?

2. How does on-campus employment facilitate and/or hinder students' academic and social integration?

3. How does students' experience of employment on campus impact their overall satisfaction with their college experience?

This study explores students' perspectives of how their on-campus employment affects their experience as students. This study contributes to higher education scholarship by articulating how different aspects of working on campus enhance or interfere with students' development and integration from the perspective of the students themselves. This knowledge will enable us to construct learning environments within our student employment positions that are tailored to enhancing opportunities for students to integrate academically and socially within the university. Given that students who have the greatest need (that is, those of the lowest SES) work the most and are vulnerable to attrition, this study may highlight an opportunity for serving a vulnerable population.

\section{Overview of Methods}

Qualitative research methodology was used in this study because the research explores how students were affected by their employment and there is little existing research to guide the study. By encouraging students to tell their stories and then 
examining those stories with a critical eye, I can get a better understanding of the broad spectrum of their experiences. Qualitative research is appropriate for this study because the focus is on the way students experience the complex social phenomenon of oncampus employment (Marshall \& Rossman, 2011).

\section{Participants}

Because the number of undergraduate students working on campus is high, themes that emerged from this study may have broad impact across higher education. All employment examined in this study was on-campus employment because this is the area in which practitioners can exercise the most control, especially in the area of Student Affairs. Participants were all undergraduate students who are returned for a second year to their place of employment on the campus of a large urban university in the Pacific Northwest. They were referred to the study through professional contacts the researcher had with student-worker supervisors.

To ensure a breadth of experiences, students' jobs were split into three categories based on the amount of autonomy and responsibility they have, and the amount of supervisory support or guidance they receive. There are at least three participants in each of these categories. The categories are described in Chapter 3.

\section{Data Collection and Analysis}

Data was collected over the summer and early fall of 2012, in 11 interviews with students. Four interviews were coded using open coding before saturation was reached. 
After all interviews were coded the codes were analyzed, yielding rich descriptions of students' experiences of working on campus.

\section{Organization of the Dissertation}

This paper is organized into six chapters. Chapter 2 will ground the study in the context of existing literature and research. It offers an overview of the problem from a research standpoint, reviewing literature that describes previous research in the area of

student employment as well as student development, academic and social integration, and satisfaction.

In Chapter 3, the rationale for the study is discussed and the methods of inquiry are explored. Additionally, notes are given about the participants in the study and the methodology is explained. An overview of the data collection and analysis are shared, and limitations and researcher bias are discussed.

In Chapter 4, the five themes that emerged from the data are shared and explained, and Chapter 5 discusses how the data answers each of the three research questions, offering a discussion of the findings, connecting them to existing literature, and drawing conclusions.

Finally, Chapter 6 concludes the paper with a discussion of implications for both scholarship and practice in student affairs. 


\section{CHAPTER 2: Literature Review}

Ideally, all of students' on-campus experiences would contribute to their learning and development. However, because students who are employed on campus are typically viewed through the lens of employment rather than student development, we fail to establish additional opportunities for student growth and development in programs most frequently used by students with limited resources (Salsbury, et al., 2009). "If higher education institutions intend to successfully enroll, educate, and graduate all students equally, it is critical to develop a clear and thoroughly nuanced understanding of the effects of work on full-time undergraduates across the broad landscape of postsecondary education" (p. 3).

This chapter will begin with a discussion about the changing demographics of students who work during college and factors influencing their decisions to work. Next, it introduces the conceptual framework and a visual model used for this study. It then explores components of the model, defining them and situating them within the student employment literature. The chapter concludes with recommendations from the literature for further research and practice, situating this study within the context of current scholarship.

\section{Who Works and Why}

In their 2005 literature review, Tuttle, McKinney, and Rago illustrate the idea of a "new majority" definition of college students. Fewer than $27 \%$ of US college students are characteristic of the traditional college student (white, middle class, dependent on his or 
her parents and graduating within four years). Students matriculating into United States colleges in the $21^{\text {st }}$ century are older, more often female, less often white and less often financially supported by their families than any time in the history of higher education.

There has been a significant increase in student employment over the last 40 years (Tuttle et al., 2005). High rates of student employment have been documented. In 2008, the National Center for Education Statistics (NCES) (Staklis et al., 2010) reported that nearly $80 \%$ of students pursuing an undergraduate education worked while attending school. The National Survey of Student Engagement (2008) results showed that half of all fulltime first year students and three quarters of all seniors attending four-year colleges and universities reported working for pay. The NCES (Staklis et al., 2010) reported that for the 2007-08 academic year, only a quarter of undergraduate students at public, 4-year institutions did not work at all during school, and students who did work logged a median of 24 hours per week. These figures demonstrate that student employment coupled with attending college is not an isolated phenomenon; this is an important area of study because of the large number of students affected.

Financial need is the primary reason students work (Lundberg, 2004). Any scan of local and national news sources highlights an increasingly dire financial climate for education in the United States. Governmental funding for higher education in the United States has dropped significantly over the past decades, even as enrollments and costs have risen. While this is a long term trend, it has increased exponentially in the face of the country's most recent recession (Sarasohn, 2010). "This downturn is not only the 
longest-recorded postwar recession but also broader than previous ones, in terms of geography and sectors," notes Scott Pattison, director of the National Association of State Budget Officers. "This time, every state has been affected and every sector has been hitbanking, real estate, autos, retail, you name it" (as cited in Sabo, 2010, Introduction section, para. 4). Furthermore, the longer and broader the recession, the longer the time to recovery (Pattinson as cited in Sabo, 2010).

Economists agree that the recession started in December of 2007 and ended in September of 2010. States have not yet recovered, however, and the ripple effects continue to rock higher education nationwide. This is certainly the case in Oregon, which has struggled for decades to fund its higher education system. Since 1990, Oregon has fallen from $34^{\text {th }}$ in per-capita spending on higher education to $46^{\text {th }}$ in 2010 (Sarasohn, 2010).

The economic situation in the United States and a neoliberal political climate have both contributed to the erosion of state and federal support of higher education (Sarasohn, 2010). This erosion has led to an increase in student tuition and fees on campuses (Sarasohn, 2010) as well as a decrease in scholarships and need based aid (Pusser, 2010). Because tuition is rising and governmental support through loans and grants has diminished, students require a way to fill the gap between their financial needs and available support, and they fill this gap with wages they earn (Pusser, 2010). This trend shows no sign of reversing or slowing, so it seems that the trend toward students' increased employment rates during their college years will also continue. 
While students primarily work for financial reasons, they report working for other outcomes as well. Scholars have determined that student employees developed workplace competencies and that students with work experience were more attractive to employers (Pascarella \& Terenzini, 2005; Heiselt \& Bergerson, 2007; Derous \& Ryan, 2008; Kasworm, 2010). Perna (2010a) echoes this, adding that some undergraduates use employment during their college years to explore career options. Finally, Kasworm (2010) states that for some undergraduates, particularly nontraditional students, being employed is closely tied to their personal identities.

Both establishing a body of work experience and developing a sense of professional identity are important to new graduates' ability to obtain employment after they graduate. Having a college degree is no longer enough to ensure success postgraduation, and students are increasingly expected to gain work experience during their college years to have a competitive edge over other graduates (Derous \& Ryan, 2008).

Perna (2010) also suggests that other, non-financial outcomes of student employment should be explored. She asserts that when we examine student employment through the lenses of why students work, this blend of personal and economic pressures calls us to "consider ways to transform employment into an experience that can enhance students' intellectual development” (p. 33). Student employment, she says, needs to be reconceptualized as an experience that benefits students' educational outcomes. 


\section{Conceptual Framework}

The conceptual framework for understanding the literature and research related to this study is based on the assumption that student development can be realized through on-campus employment. Next, the framework introduces academic and social integration, situating it within the context of student employment. Student satisfaction is then examined as an outcome of academic and social integration realized through student employment. All of these components build to an outcome of retention and persistence (See Figure 1 for a visual model). In the section that follows, the concepts framing this study will be defined and situated within the existing literature.

\begin{tabular}{|c|c|c|c|}
\hline $\begin{array}{c}\text { Aspects of } \\
\text { Student } \\
\text { Employment as } \\
\text { Student } \\
\text { Development }\end{array}$ & $\begin{array}{c}\text { Academic and } \\
\text { Social } \\
\text { Integration }\end{array}$ & $\begin{array}{c}\text { Student } \\
\text { Satisfaction }\end{array}$ & $\begin{array}{l}\text { Retention/ } \\
\text { Persistence }\end{array}$ \\
\hline
\end{tabular}

Figure 1: Conceptual framework.

\section{Student Development}

Clearly, colleges and universities have goals for their students. Student development theories can be a useful tool to both articulate the goals of attaining a higher education and describe the process by which that happens. Useful outlines by Bowen (1977), state that higher education has three goals in terms of student development: cognitive learning (development of knowledge base and ability to learn new things), affective development, which he defined as "enhancing their moral, religious and emotional interests and sensibilities" (p. 39) and practical competence, the ability to live 
and function in key parts of society including work, citizenship, family life, and other areas.

Chickering and Reisser (1993) felt that establishing a sense of personal identity was a critical element for students' development in college, describing student development as occurring along seven vectors. Development is organic: it doesn't happen in stages, and often occurs in more than one vector at a time. Additionally, students can visit and revisit vectors as they continue to develop along that domain. In addition to establishing identity, the seven vectors outlined in this revised theory include emotional development elements (including managing emotions, moving through autonomy toward interdependence, and developing mature relationships) as well as intellectual considerations (such as developing competency and purpose) and social aspects (like developing integrity and establishing identity). This theory of student development is centered on the idea that professionals in student affairs have the ability to create environments at their institutions that enable students to move through these vectors and develop more fully throughout their college experiences.

In addition to exploring what students should gain from their college experience, scholars have worked to understand the way that students connect to their institutions so they can develop in those ways. Astin's (1984) Student Involvement theory is simple: students develop in direct relationship to the amount of time and focused energy they expend in educationally purposeful activities, suggesting powerfully that the most important institutional resource any college had was student time. The idea of 
involvement was also a key element of Tinto's (1993) theory of student departure. Like Astin's model, his examined institutional impact on the dynamics of students entering college with a set of characteristics, intentions, and habits. Students encountered an institutional setting, and their personal characteristics led them to integrate on varying levels with the social and academic life of campus. This level of integration was strongly correlated with their persistence. More than Astin's, Tinto's model focused on student departure and sought to determine influences on students who drop out of school.

These theories were key elements in the development of the Student Engagement Theory (Kuh, 2001). In it, the idea of student effort interacting with institutional environments was paired with a strong push for the creation of educationally purposeful activities for students. Said another way, whereas students develop based upon their interaction in educationally purposeful activities, institutions have the power to build these activities and make them compelling enough to draw student interest.

Another important concept closely related to integration is mattering. Integration involves students' feelings about their institution, whereas mattering is related to a students' perception of how their institution feels about them. The concept is rooted in Maslow's theory of the hierarchy of needs (1970). France and Finney (2009) describe this theory as rooted "specifically in the need to belong... after the needs of physiology and safety are met, the need for belongingness emerges" (p. 104). Several scholars worked to hone the idea and develop a measurement of constructs related to mattering, including Rosenberg and McCullough's work to define the construct (1981), and 
Schlossberg, Lynch and Chickering's model of how mattering would impact adult learners (1989). Study on this construct continues currently in the field. Eliott, Kao and Grant (2004) have developed a University Mattering Scale to help measure student's sense that they matter within their institution. The four constructs of Awareness, Importance, Reliance and Ego-Extension are important elements of a student's experience of mattering within a university setting.

Scholars have been exploring the effects college has on students, and what factors influence students' ability to remain in school, graduate, and get the experiences that allow them to develop. Scholarship has looked at those experiences both in a broad sense and a narrow one, focusing on influences of various factors, including employment, on student outcomes (see Pascarella \& Terenzini, 2005 for a metaanalysis of the literature).

\section{Student Employment}

It is important to begin with an understanding of existing research on Student Employment. This section will discuss employment through position types and will then offer a discussion of student employment as student development.

Position types. Research into student employment has barely begun to consider differences in the types of roles and responsibilities that account for student employment. It hasn't accounted for the specific dynamics of the workplace, including the level of meaning students contribute to the position (Cheng, 2004) or how relevant the work is to their studies or academic career (Derous \& Ryan, 2008). 
According to Wolf-Wendel et al. (2009), research on student employment "that utilizes involvement theory measures time on task more than it does the expenditure of energy" (p. 411). Not only is the amount of time put into an educationally purposeful activity important to student learning, but also the quality of that engagement (Astin, 1984). Therefore the different kinds of educational activities students engage in will have varying impacts on their experience on campus. It stands to reason that different kinds of work would offer different ways for a student to develop as well. Therefore, student employment may have an impact on outcomes. For example, student employment positions that take place in educationally purposeful settings or that offer intentional learning and development goals may have a different impact on student employees than settings that are not educationally purposeful and where developmental goal setting has not taken place. Research to date has not considered differences in types of jobs held by students who work (Riggert et al., 2006; Salsbury et al., 2009), such as different work roles and different relationships students have with those they work with (Lundberg, 2004).

Employment as student development. A student developmental approach to understanding student employment's effect on college students is reinforced in the literature. Chickering and Reisser (1993) stated that student employment offered an opportunity for students to develop along the Establishing Identity vector.

Cheng's (2004) mixed method study of the nature of the impact working had on student outcomes supports this approach as well. Students in his study reported that when 
they found work meaningful, or when they found meaning in their work that they began to truly appreciate the value of the work and consider it an integral part of their college experience. Furthermore, positive perceptions students have about their employment and its impact on their overall success were largely related to the degree of challenge they felt the position offered and the importance of the work. First year students who began their employment experiences in more menial roles “often felt bored and useless" (Cheng, 2004, p. 12). Therefore, students who felt challenged by work that they perceived as important viewed their employment as an integral part of their college experience.

Similarly, Derous and Ryan (2008) found that outcomes, including GPA, sense of well being, and attitude about studying, were enhanced by the amount of autonomy to determine job tasks and autonomous motivation (that is, motivation to perform based upon enjoying the job rather than the need to avoid shame) that some of the positions offered.

\section{Academic and Social Integration}

This study imagines student employment as a developmental experience. To explore this idea further, employment will be examined through the lens of Academic and Social Integration, concepts developed by Tinto (1993). Academic and Social Integration Theory has long been the leading theoretical framework used in research related to student persistence in higher education (Beekhoven, DeJong \& VanHout, 2002). Integration is the term used to explain the degree to which students identify with their 
campus community, and their level of congruence and commitment to the institutional culture (Tinto, 1993).

Tinto (1975) first introduced the idea of Academic and Social Integration in his Student Integration Model of Attrition. The model is used to explain why students either persist or drop out of college voluntarily, and the model has been explored and expanded since its creation (Canberra, Nora, \& Castaneda, 1993). The idea of the model is that students begin college, bringing with them a set of background characteristics and experiences. The students become involved with the college environment both socially (through peer contact and extracurricular activities) and academically (pursuing academic achievement, connecting with the intellectual energy of the campus, and interacting with faculty). The term "integration" refers to the degree to which students adopt the normative attitudes and values of the institution, and abide by the formal and informal rules and norms that govern the university community. This integration informs their sense of satisfaction with college life, which in turn influences their persistence. Said another way, integration theory suggests that students' level of persistence is strongly correlated with the sense of connection they have developed with their institutions, relative to their sense of identity and connection to off-campus, nonacademic influences (Tinto, 1993).

The constructs of academic and social integration have repeatedly been found to be predictive of student persistence (Milem, 1998; Pascarella, 1982; Pascarella \& Terenzini, 1980; Strage, 1999; Cabrera, Nora \& Castaneda, 1993). Additionally, a variety 
of cognitive and personal advantages have been identified for students who score high on measures of academic and social integration with their campus environments including attitude (Milem, 1998), satisfaction (Pascarella, 1982), and motivation (Prospero \& Gupta, 2007).

Academic integration in student employment research. Measures of Academic Integration include interaction with faculty members and academic performance. Both have been the subject of scholarship in the area of student employment. Lundberg (2004) assessed interaction with faculty members as part of her study. She found that while working hindered involvement for student workers, it did not have a negative effect on learning. Students who worked 20 hours or more reported less faculty interaction and a poorer quality of nonacademic peer relationships than their nonworking peers. However, despite these negative involvement outcomes, "there were no differences in learning based on the number of hours students worked" (Lundberg, 2004, p. 206). In her study, learning was measured by 22 different variables that assessed students in the areas of general education, intellectual ability, scientific knowledge and personal ability.

Most scholarship on student employment has focused on grades as academic performance, which is another measure of academic integration. According to Pascarella \& Terenzini (2005), “Virtually without exception, students' grades make statistically significant, frequently substantial and indeed often the largest contribution to student persistence and attainment" (p. 397). Several studies report that working can have a negative impact on student grades. For first year students, work experiences were directly 
related to grades in college, and grade performance was dependent upon the amount of hours spent working each week (Pike et al., 2008). Additionally, students with oncampus employment performed better than students working off campus. Wentz and $\mathrm{Yu}$ (2010) found that working during the academic year had a modest but statistically significant negative effect on student performance, however their analysis agreed with Pike et al.'s (2008) assessment that students working on campus earned higher GPAs than their off-campus working peers.

Light (2001) found no relationship between work and grades, but did not delve into differences between types of employment. Pike, et al. (2008) began to address the differences in employment types when considering the purpose of the activity, "Students' work experiences are significantly related to their levels of engagement in educationally purposeful activities, and these relationships have important consequences for the indirect relationships between work and grades" (p. 574). Wentz and Yu advocated examining the type of position that students held on campus as part of the student success equation. They found that working could negatively affect student grades, but they added that students who viewed employment as complementary to their academic pursuits enjoyed better academic performance than students who did not see that relationship. This assessment is echoed by Kuh (1995), "students benefit from employment when they perceive that their academic as well as personal goals are being met" through their jobs (p.148). 
Astin (1993) stressed that student involvement was an excellent indicator of student success, particularly as it related to academic pursuits and relationships with faculty and peers. In this earlier research, Astin stated that working during school takes a student's attention away from involvement in educationally purposeful activities. However, in a study aimed at quantifying the effect of work on student grades, Wentz \& Yu (2010) found that students who work in order to gain skills specific to their desired career path perform better in the classroom than students who work for other reasons. Similarly, Tuttle et al. (2005) found that although it runs counter to prior research, emerging scholarship "strongly indicates working to be beneficial to student success... [working helps students]...focus on academic work" (p. 8). Furthermore, both Furr and Ellig (2000) and Lundberg (2004) found that on-campus employment led to greater interaction with faculty members relative to working off campus.

The nature of the positions themselves, the relationship positions have to students' future goals, and the opportunities to interact with faculty members outside the classroom setting all may have implications for students' academic integration. These studies indicate a need to further examine the nature of student work in efforts to maximize the academic transferability of their work experience.

Social integration in student employment research. Integration and involvement are related concepts. According to Kuh and Sax (cited in Wolf-Wendel et al., 2009), integration is a result of becoming involved on campus. The term reflects a sense of belonging that happens after students engage in purposeful academic and social 
experiences. Integration and involvement are both closely linked to engagement; therefore, all three measures will be included in this section of the literature review. Earlier research focused on the negative impacts of working. Tinto's work on student attrition (1993) came from the same position as Astin's (1993) work, determining that employment limited time students could spend on both studies and interaction with faculty and other students, which are related to students success. "As a consequence, one's social integration as well as one's academic performance suffers" (p. 269).

More recent scholarship has revealed that this position may not always be accurate. In fact, there seem to be different outcomes when students work on or off campus. Working on campus appears to have positive correlations with student involvement in clubs and organizations, according to a study by Furr \& Ellig (2000). However, higher numbers of hours worked off campus were linked to less interaction with peers and other parts of campus life such as clubs and organizations. Regardless of the number of hours students worked either on or off campus, interaction with peers on an academic level was the strongest predictive factor for student learning (Lundberg, 2004). Student involvement with peers, an important part of social integration (Tinto, 1975), must be part of our research into student employment, according to Wolf-Wendel et al. (2009). These scholars assert that involvement "has been linked via research to almost every positive outcome of college" (p. 412).

Interaction with peers is an important component of social integration. The effects of student on campus employment on the amount of time and energy students can spend 
in these social endeavors may have implications for their ability to integrate successfully with college life.

\section{Student Satisfaction}

The final construct on which this study is based is Student Satisfaction. Student satisfaction is defined as a complex phenomenon that covers the students' subjective experiences during the college years and their perceptions of the value of those experiences (Astin, 1993b). According to Bowen (1977), people usually spend between one sixth and one third of their lives in formal education. "Personal satisfaction and enjoyment is by no means a frivolous goal. And it becomes even more important when one considers that enjoyment of education undoubtedly enhances its effectiveness" (Bowen, 1977, p. 44).

Student satisfaction is a key indicator of institutional effectiveness and success, and assessment of student satisfaction is closely linked to overall quality improvement efforts within higher education (Donald \& Denison, 1996; Beltyukova \& Fox, 2002;

Schuh \& Upcraft, 2000). Measuring student satisfaction is important for maintaining and increasing enrollment, managing attrition and retention problems, and making betterinformed decisions in higher education (Beltyukova \& Fox, 2002). Satisfaction also has been found to be positively related to student motivation, retention, and persistence (Beil \& Shope, 1990; Knox, Lindsay, \& Kolb, 1992; Lenning, 1982; Pascarella, 1982; Elliott \& Shin, 2002; \& Astin, 1993; Tinto, 1993), and academic performance (Elliott \& Shin, 2002). 
The importance of students' satisfaction to their persistence is unambiguous. Astin (1993b) believed that satisfaction was one of the most direct measures of success in college, deserving to be measured alongside all other important educational outcome constructs. The scope of this study does not include retention and persistence; however, student motivation (Schweinle \& Helmling, 2011) and satisfaction (Tinto, 1993) are proxies for retention, and so are vital to understand.

\section{Employment Factors Related to Retention and Persistence}

This study situates on-campus student employment as a student development phenomenon. Students' ability to integrate academically and socially with their campus is important to their satisfaction. Because satisfaction is closely related to students' persistence through school, this is an important area of study.

According to the Center for the Study of College Student Retention (2012), understanding persistence and retention is important because identifying factors related to students returning from one term to the next and persisting to graduation can help an institution identify areas to improve their effectiveness. Researchers have studied the effects of working, both on campus and off campus, on student retention.

Scholarship shows different results for students who work on campus verses students who work off campus. An on-campus part-time job has a positive effect on retention and completion of a bachelor's degree (Astin, 1993; Cermak \& Filkins, 2007). Other studies have shown on-campus student employment to have a curvilinear relationship to retention (Horn, Malizio, \& NCES, 1998; Kuh, 1995; Kulm \& Cramer, 
2006). That is, students who worked 1 to 15 hours per week were found to have the lowest risk for stopping or dropping out, and students who did not work at all left school at rates comparable to student who worked 16 to 34 hours every week. Students working over 35 hours per week were found to have the highest incident of dropping or stopping out of school.

By contrast, working off campus for any number of hours was slightly negatively correlated with retention (Kuh, 1995; Kulm \& Cramer, 2006). Studies have also suggested that student persistence and learning measures were linked to positions in which students saw relationships between their employment and their studies or career interests (Broughton \& Otto, 1999; King \& Bannon 2002). Researchers agree on the importance of both further study in the area of on-campus employment and establishing carefully constructed environments for learning within the student employment setting.

\section{Gaps in the Research}

Much work has been done to determine how working during school effects college students. We know that the majority of students work, and we know that the numbers are growing. We also know that the political and economic climates indicate that this trend is not likely to reverse. We know that the relationships between working and student outcomes are complex and dependent upon many different variables.

In addition to the context that makes it necessary for students to work and the academic, social, and affective outcomes discussed above, research in the area of student employment has covered additional of areas. Studies have examined professional 
development measures such as time management and prioritization (Wentz \& Yu 2010; Pascarella \& Terenzini, 2005), decision making, group process and teamwork, communication and critical thinking (Cheng, 2004) and student leadership measures (Lewis, 2010; Derous \& Ryan, 2008; Kuh, 1995). Many scholars have weighed in on the relationship between work and student outcomes, but while scholars can agree on the importance of additional study, existing research is far from unanimous in its findings about the impact of employment on college students' performance. We do not know how working is related to student success, or if that relationship is positive or negative in aggregate (Riggert et. al, 2006; Derous \& Ryan, 2008; Salsbury, Padgett \& Pascarella, 2009).

There is a need for further research, and the focus of the research needs to shift to a more cohesive approach that stresses well-defined variables and definitions (Riggert et al., 2006). "Generally speaking, when the findings of research on a given topic are consistently inconclusive or contradictory, it is time to revisit the premises at the heart of the research" (Pusser, p. 136). Lundberg (2004) discussed exploring the area of transferability of work experiences with classroom learning. She calls for research that identifies elements of employment that are conducive to academic integration and learning on campus. Furthermore, she advocates investigating specific "work roles, work relationships, and the degree to which the students' employment is related to his or her classroom learning" (p. 209) to see if that helps explain some of the variance seen in the impact of working on student learning. 
Finally, scholarship has yet to delve into differences in types of jobs held by students who work (Riggert et al., 2006; Salsbury et al., 2009). By studying student outcomes related to different types of on-campus employment in tandem with a consideration of the characteristics of these positions that students most feel helps and hinders their development, integration, and satisfaction, we can further our understanding of the impact employment has on students.

\section{Study Purpose and Potential Contribution}

This study adds to our understanding of the impact working on campus has on students' development, academic and social integration, and satisfaction, which ultimately contributes to students' persistence and retention. The study reframes oncampus employment as an avenue for student development, exploring how students experience employment on campus and how it influences their sense of satisfaction with their total college experience.

This is an important area of study because what we discover will have implications for a significant percentage of college students. The stakes are even higher because students who work tend to be those who have the greatest economic need (Tuttle et al., 2007) and students of limited financial means are more likely to be students of color and first generation college students (Pascarella \& Terenzini, 2005). Financially disadvantaged students, students of color and first generation students are retained and graduate in lower numbers than their peers (Pike \& Kuh, 2005; Pascarella \& Terenzini, 
2005; Bozick, 2007), therefore scholarship that could further our understanding of what challenges and sustains these students in college is valuable. 


\section{CHAPTER 3: Methodology}

This study seeks to identify aspects of student employment that are not yet clearly understood (much less agreed upon) by existing literature. It explores the experience students have working on campus and examines the parts of their employment that help and hinder their development as well as their integration and satisfaction with their college experience. This chapter describes the methodology of the study. It begins by reiterating the research questions followed by a description of the research site and the study participants. The next section highlights the development of the study design. The final sections include the methods of data collection and analysis, study limitations, and researcher bias.

\section{Focus of the Study and Research Questions}

The purpose of this study is to examine on-campus employment from the perspective of student workers who persisted in their jobs and in their academics after a year of on-campus employment. The three questions addressed in this project are:

1. How does on-campus employment facilitate and/or hinder students' development?

2. How does on-campus employment facilitate and/or hinder students' academic and social integration?

3. How does students' experience of employment on campus impact their overall satisfaction with their college experience?

This study addresses some gaps in current research. It contributes to understanding the ways in which working is related to student success, and if that 
relationship is positive or negative in aggregate (Riggert et al., 2006; Derous \& Ryan, 2008; Salsbury, Padgett \& Pascarella 2009). The project also identifies elements of employment, including work roles and relationships, that are conducive to academic integration and learning on campus (Lundberg, 2004). Finally, this study fills gaps in the literature as it articulates the student outcomes related to different types of on-campus employment and the characteristics of these positions that students most feel helps and hinders their development, integration, and satisfaction (Riggert et al., 2006; Salsbury et al., 2009).

\section{Study Rationale}

The knowledge to be discovered in this study is based on the lived experiences of participants; therefore, a qualitative approach is called for (Cresswell, 2007). One of the most common forms of qualitative research found in education is the Basic Qualitative Study (Merriam, 2009). In this type of inquiry, researchers try to identify how people make sense of their experiences, how they construct reality from those experiences, and what meaning they assign to those experiences. Instead of testing an established model, researchers gather open-ended, qualitative information and use a defined process to organize that raw data into concepts, drawing conclusions about the themes that emerge from an analysis of the collected experiences of participants (Merriam, 2009).

A narrative approach (Merriam, 2009) was used in this basic qualitative study. Students were asked to describe their experiences of student employment and comment on how their jobs impact the things they do and the way they feel about being a student. 
Their narratives were analyzed through a series of coding approaches, and the themes that emerged illuminate the impacts of working on their ability to develop as students and integrate both socially and academically with the campus. The study also explores the ways working helps and hinders students' motivation and overall satisfaction with their college experience.

\section{Site}

The site for this study is a large, urban university in the Pacific Northwest with an enrollment of approximately 30,000 students. The institution employs approximately 1700 students in a variety of roles across campus. Nearly $50 \%$ of the university’s undergraduates are transfer students, and the average age of undergraduate students is 26 years.

\section{Population and Sample}

This is a qualitative research study, which stresses in-depth investigation of a distinctive group of people (Cresswell, 2007). The goal of this study is to focus on the lived experiences of students who work on campus. Purposive sampling was used (Cresswell, 2007) to hone in on the experience of currently enrolled students who view their primary role on campus as "student" as opposed to fulltime employees who are also earning a bachelor's degree. In addition, the sample only included students who were in at least their second year of both enrollment and student employment. Furthermore, this study was limited to exploring the experiences of undergraduate students. 
Another purposive sampling criteria used in this study was Job Type. It is important for this study that the students involved represented a broad range of positions. Therefore, their positions were split into three different categories based upon the level of autonomy and challenge they offered. To categorize the positions, I worked with colleagues who supervise students, using the guidelines from the study campus' Human Resources department to assist in dividing students into different job type categories.

The three categories of Job Types used in this study were: positions that have a high level of autonomy and challenge balanced with moderate to high supervision (this category includes RAs, and Program Coordinators); positions that have a medium level of autonomy and challenge balanced with moderate supervision (including the Student Ambassadors, Peer Mentors and Campus Recreation employees); and positions that have a low level of autonomy and challenge coupled with a high level of supervision (including students working in receptionist roles). These categories were assigned through working with supervisors of students known to the researcher through committees on the study campus that addressed student employment and student leadership positions. Developing an empirical framework is not necessary because the intent of the categorization was to ensure a breadth of employment experiences, not to quantify outcomes.

Approval through the study institution's Institutional Review Board was sought and granted in May of 2012 (see Appendix A). Supervisors were asked to provide names and email addresses of all undergraduate students that they had for given positions 
worked in their position at least six months and were returning for another year of employment. Requests were sent by email to the pool of twenty-six students (see Appendix B), and several follow up emails were sent. All of the eleven students who responded were scheduled for interviews, also via email, for the study.

Table 1 identifies each participant with their assigned pseudonym, the position title, and the job category. The three categories were equally represented in the study with at least three participants each.

Table 1: Study Participants by Position Type

\begin{tabular}{|l|l|l|}
\hline \multicolumn{1}{|c|}{ Name } & \multicolumn{1}{|c|}{ Position } & \multicolumn{1}{c|}{ Type and Explanation } \\
\hline Rusty & Reception & Type I: very low autonomy and responsibility, high supervision \\
\hline Gail & Reception/ Records & Type I: very low autonomy, moderate responsibility, high supervision \\
\hline Graham & Reception & Type I: very low autonomy and responsibility, high supervision \\
\hline Jason & Ambassador & Type II: moderate- high autonomy, low responsibility, high supervision \\
\hline Rick & Peer Mentor & Type II: moderate autonomy, shared responsibility, moderate supervision \\
\hline Bradley & Peer Mentor & Type II: moderate autonomy, shared responsibility, moderate supervision \\
\hline Jack & Rec Sports Supervisor & Type II: moderate autonomy, moderate responsibility, moderate supervision \\
\hline Chris & Rec Sports Supervisor & Type II: moderate autonomy, moderate responsibility, moderate supervision \\
\hline Quinn & Program Coordinator & Type III: high autonomy and responsibility; moderate supervision \\
\hline Anne & Resident Assistant & Type III: high autonomy and responsibility; moderate supervision \\
\hline Ethan & Resident Assistant & Type III: high autonomy and responsibility; moderate supervision \\
\hline
\end{tabular}

\section{Design Framework for Inquiry}

The data for the study were generated through interviews with student employees over the summer and fall of 2012. The interviews were based on an interview template developed for this purpose (See Appendix D), and the interview format was semi- 
structured to put students at ease and to maximize their flexibility in answering the questions.

The design framework for this study was developed through a consideration of Astin's Input-Environment-Outcome (I-E-O) model of exploring student persistence (1993) and Tinto's (1993) Model of Integration using relevant scholarship on student employment, including Perna (2010), Riggert et al., 2006, and Derous \& Ryan (2008). In the I-E-O model, Astin posits that students bring to campus a certain set of characteristics. They then enter the university setting and encounter programs, faculty members, peers, and academic and social experiences. The outcome construct is a measure of the way that the student (with their 'input' characteristics) changes as a result of their interaction with the campus environment.

Tinto's (1993) model is similar, and also addresses the ways in which academic and social systems both directly and indirectly affect one another. He notes the importance of students integrating with campus socially and academically, describing integration as the degree to which students adopt the norms, values and behaviors espoused by the campus community.

\section{Interview Overview}

After introducing myself and the study, the first section of each interview gathered demographic information from the students, including their position title, major, and year in school. 
Then, the focus of the questions shifted to the students' jobs, wherein the questions addressed characteristics of the positions students held. Perna (2010) advocates researching students' employment experiences as a whole. She suggests that whereas research has been done related to the financial benefits of working, that researchers explore other elements of employment.

Students then were encouraged to describe the type of tasks they did on a regular basis, and their level of autonomy in directing their work. According to Wolf-Wendel et al. (2009), "much of the research that utilizes involvement theory measures time on task more than it does expenditure of energy" (p. 411). Not only is the amount of time put into an educationally purposeful activity important to learning, the quality of engagement is as well (Astin, 1984). Because different types of educational activities affect student learning differently, it stands to reason that different types of employment would affect students differently as well.

The interviews also addressed communication with other students and faculty, and sought to identify the nature of the conversations (work, non-work, academics, or all three). This was followed up by specific questions about relationships with coworkers and the student's supervisor. A question about the nature of supervision was included both because it may be related to academic or social integration directly, depending on the nature of the position, but also because the level of challenge and support the student receives from his or her supervisor is relevant. Supervisors who offer a more optimal balance of challenge and support create what Dalton and Crosby (2010) refer to as 
"positive restlessness," which they describe as "creative disequilibrium and intellectual foment that drive personal exploration and development" (p. 2).

The final area for examination in this area explored the level of challenge students felt in their jobs, the support they received, and the relevance of training or orientation programs. Research indicates that differences in the level of challenge and autonomy students perceive in their positions has an influence on outcomes (Derous \& Ryan, 2008).

The final section of the interviews addressed ways in which students' jobs affected them. Questions were asked about what activities they engaged in while on the job, as well as how working impacted use of their personal time. Through prompts used in this part of the conversation, students described how working impacted their social and academic pursuits.

Finally, students were asked how they were enjoying their college experience overall. If not evident, students were prompted to comment on the ways in which their work on campus affected that satisfaction, a measure that is strongly correlated with persistence and retention (Tinto, 1993).

\section{Data Collection}

The purpose of this study is to understand aspects of student employment that help and hinder their levels of academic and social integration and their overall satisfaction with the college experience. The study is designed to examine student employment from the perspective of students themselves. 
The General Interview Guide Approach was used. According to Turner (2010), the general interview guide approach allows the researcher to ensure that the same categories of inquiry are used with each subject while still enabling a degree of flexibility for the researcher to ask more probing questions or focus on one or more elements that the subject suggests. This study was broad, covering many areas, and the interviewees had a broad range of experiences to discuss. Building in flexibility was important to the outcomes because students were able to give extra attention to the items in the study that are most pertinent to them and most applicable to their personal employment story.

The interviews were digitally recorded and transcribed by the researcher. Follow up questions were asked of two participants when it became evident that not all of them commented on their longer term goals. These participants were emailed with the questions, and they responded via email as well.

Interviews ranged from 30 to 90 minutes, and took place in the researcher's office, a private location well away from students' places of employment to allow them to feel more comfortable sharing information. Informed consent forms were discussed and signed by each participant (see Appendix C), and each participant received a $\$ 5$ gift card from Starbucks Coffee as a sign of appreciation for their time.

\section{Coding and Analysis}

The constant comparative method (Cresswell, 2007), was used throughout the data collection and analysis processes. This method is based upon inducing emerging themes in the data, identifying elements connected to those themes and grouping them 
into categories. Information from the data was then compared to these emerging categories, which were recorded through use of both a written journal and digital spreadsheets.

All data were coded manually and open coding was used until saturation was reached. This happened after four interviews were coded, and the data yielded just over 200 codes. Then axial coding (Marshall \& Rossman, 2011) was used to group the codes into broader categories which became themes and sub-themes. These initial codes answered the question "How do students describe their jobs?" resulting in an initial list of themes (see Appendix E). The first five of these became the descriptive themes in the study because they all emerged directly from the questions asked of participants.

After this initial coding and clustering, it became clear that the data was saying something else. At this point, the codes were arranged visually and clustering was used to illuminate the relationships between the codes (Marshall \& Rossman, 2011). This clustering highlighted another important question to ask of the data which was, "what are they discussing?" Analysis through this approach helped more clearly articulate a different perspective on the data which was analytical rather than just descriptive. Through this analysis, it became evident that some codes could be interpreted in more than one way. In re-analyzing the codes, I used a process of simultaneous coding (Saldana, 2009). This type of coding “is appropriate when the data's content suggests multiple meanings and justify more than one code" (p. 62). The first alternative interpretation to emerge was around the concept of "I matter." This included students 
describing feelings that their supervisors cared about them and wanted them to succeed which sounded similar to my understanding about mattering. When I reviewed the Mattering model (Eliott et al., 2004) and compared the data with the categories that compose it, it was clear that mattering was an important part of students' experiences.

As I reviewed the codes through the approach of "what are people talking about?" data about personal and professional development also emerged and became the basis for a second interpretation. Students discussed developing professional competencies that will help them in their careers and their studies. They talked about learning how to deal with tough emotional situations, and times when their positions put them in situations that tested their integrity and showed them the value of working effectively on a team. These areas sounded like student development theory to me, so I revisited Chickering \& Reisser's (1993) work on the vectors of student development. Comparing the seven vectors to the data, I found that all seven of the vectors were addressed in the experiences students described.

\section{Limitations of the Study}

This project has two notable limitations: the site and the participants may not be representative of student employees' experiences across the spectrum of higher education. First, the university at which this study takes place is a large, urban public university setting with a commitment to learning out of the classroom setting. Service learning is an important component in the curriculum campus wide, students are required to complete a service project as a prerequisite for graduation, and the university's core 
curriculum is built on an interdisciplinary, reflective model. This may have an effect on how students approach their work on campus. Furthermore, the student population is atypical. More than $40 \%$ of our students are first generation students, and the average age of undergraduates is four years higher than our comparator institutions. Consequently, results of this study may not translate easily to other campuses populations.

Participants also self-selected into the study. There is no way to know if the information that would have been gathered from other students invited to the study (who did not meet with me for an interview) or those I did not identify for this study would have shared different information. Finally, the sample of participants in this study is both problematic and potentially a benefit because they were all second-year employees (study sampling criteria) who were suggested by their supervisors for this research project. Supervisors are unlikely to suggest employees who are not doing a great job. Also, students in their second year of working in a position further indicates that they were successful in their roles, and were satisfied enough to return for a second year.

Therefore, the results in this study may not be true for all student employees. The benefit, however, is that data gleaned from this population of students can be held up as an example of what students experience when their on-campus employment works well for them as students.

\section{Researcher Bias}

Researcher bias needs to be considered through the lenses of both personal and professional history. On a personal level, I served in multiple employment settings as an 
undergraduate student, both on and off campus. On campus, my positions varied from working as a file clerk in a department office setting, to working as a writing tutor and peer academic advisor, to working as a business manager for a small literary triannual magazine. Off-campus work consisted of working in my family's book store and working as a cashier in a grocery store throughout my undergraduate experience. Total hours worked varied from 25 to 40 per week during the academic year.

In terms of professional history, it is noteworthy that the researcher has worked with student employees in a variety of settings, and seen students struggle with and benefit from their positions in multiple ways. Just as training and orientation is different in each setting, learning seems to be different for students who work as front desk assistants than for students working as resident assistants. In fact, the genesis for this research project was my observation that working as a resident assistant seems to be a uniquely effective professional development environment.

These experiences may translate into some preconceived ideas about what students will say about their positions, and could potentially influence interpretations or coding. To alleviate this problem, I tested the interview protocol using a pilot interview prior to its use for this study. Throughout the process, I reflected through journaling, noting responses, impressions, and questions as they arose. I worked closely with my advisor to ensure that the coding was clear, that the themes I assigned were appropriate, and that I had examined the data thoroughly. Finally, throughout the experience of 
gathering analyzing data, I consulted with my peers about my research, gaining perspective about my impressions and my approach to the analysis. 


\section{CHAPTER 4: Themes of Student Employment}

This study explores the experiences of college undergraduates' employment on campus to determine the ways that working enhances or undermines their ability to engage in student development and integrate academically and socially, as well as their overall level of satisfaction with their college experience. It seeks to understand how aspects of working influence their ability to engage in the activity of being a college student.

In this study, eleven students were interviewed. The interviews were coded using open coding and then the codes were grouped into theme areas. After coding the data, it became evident that six themes could be used to articulate these students' experience of the work they do on campus. This section will explore these themes of student employment, which include communication, relationships with peer colleagues, relationship with supervisor, academics, and on-campus activity.

\section{Communication}

For all of the individuals interviewed, their main job responsibility as a student worker was communication. On the job, they all reported communicating with students, but they also reported talking with faculty, staff and administrators, and off-campus entities such as donors, prospective students, parents and emergency services providers.

A significant amount of communication happened between student workers and their peer colleagues, and student workers and their supervisors. However, because that communication and the relationships associated with it were very distinct and significant, 
they are addressed in their own sub-theme categories. This section explores student employees' communication with their fellow university students, faculty, staff and administrators, and external entities.

\section{Students}

By far, the bulk of the work done by the student workers in this study involved communicating with students on campus. From giving directions or information, to working with new students in a residence hall or classroom setting, to overseeing campus recreation activities, student workers were employed in the business of communicating with students. Ethan said that a large part of his job was, "dealing with people on all sorts of levels to kind of help someone who is in need." Through the course of their duties, they communicated about university policies and procedures, shared information about university resources, acted as a supportive listener to students sorting out problems, and they mediated conflicts between students. Chris summed up communicating with students this way, "I always say that our jobs are not rocket science; our jobs are more about connecting with people more than anything else." He felt that communicating with others, connecting with them and getting them to understand him was at the core of his job. He said:

I definitely notice just walking around campus now-I usually walked around with my headphones on, and I can't really do that anymore because I'm constantly saying hi to people I've met through my position—-people who have 
hurt themselves or dome something silly playing a sport, you know, you see them now, and you can joke about it and laugh.

Chris viewed the important part of his job as building connections with students through communication on behalf of his department.

Several of the participants discussed the importance of building community within their roles. For the Program Coordinator, the RAs, and the Peer Mentors, building community was central to the purpose of their roles. Quinn stated, "Really, my job is to listen to the needs of the population on campus and build something that would allow them to feel safe and at home." Talking about his role as an RA, Ethan stated, I create community-I'm the spark for the fire. I give them tools and they do it themselves... I'm just also there to kind of like make sure that they are not getting too out of line, that they're healthy, that they're doing healthy habits and being the best students they can...making sure our programming and our student development... are in line with the mission of housing and the mission of the university... I'm a positive role model and that reflects down the line.

Ethan communicates with his residents to build community, establish boundaries and help them make their way through school in a positive manner.

Quinn also spoke about creating community for students, "I really like making people feel safe and connected and finding themselves, who have historically not really felt a part of anything, and being like 'you belong here."' Quinn saw building community as a central piece of his role. 
Rick also discussed the importance of communicating with students to serve as a supportive influence on them.

Sometimes students bring some very personal issues that you feel you know, you have a personal responsibility to be their friend — to be there for them—at the same time you have to keep that professional boundary that defines the role as a mentor and a peer, and that's a struggle. And what I've learned from some of the more experienced faculty members, they teach you to care about your students and look to promote their success, but don't become so emotionally invested in them that you neglect your own well being.

Rick valued his role in supporting students personally through mentorship, and navigated that role carefully.

Participants also communicated with students to enforce departmental or university policies. Jake related an experience about enforcing the policy prohibiting taking photos at intramural games.

That's the hardest part, enforcing policy... at the end of the day, I did my job...So enforcing that is a challenge. I had to go up to a few women in particular, what was really difficult was this woman who was Middle Eastern, she had the [indicates with his hands a hijab]... yeah, head scarf on, and I had to tell her that she couldn't take photos, it was kind of like, like sometimes there's a language barrier, and I don't know, kind of a cultural thing, too, like I don't want to come 
across like I'm singling this person out, but nonetheless, I go up to her and tell her she can't take photos.

Jake had to work across cultural differences to communicate with students in a respectful, welcoming way while upholding policy.

Ethan also discussed his role in communicating with students about policies, and the need to enforce them. He said, "I make the call...do I enforce this policy right here right now, or do I give a warning? [What is] going to benefit the student in the long run?" He talked with students about policies and made decisions about documenting situations to continue the communication up through his departmental channels.

Upholding standards of behavior and making decisions about the appropriate way to do that was also part of Bradley's job. In his role overseeing a group of students, Bradley had a student who was disruptive to the group's process:

Once he said something like, “that's so gay.” I was just like (sigh), I don't want to have this conversation right now, but I know this has to be addressed and I didn't address it right then. I just let it go, but then, that's a conversation we'll have later in the year and I wanted to wait until then. But that just makes me feel awful that I didn't address it right then, but it was just like, we don't have time to go into this right now, to just drop everything and address that comment, this language.

Bradley had to make a judgment call about the mentor session space: he could allow the disruptive student's comments to derail the class again and have an important 
conversation about respect, or he could keep the class on track and address the comment later.

Setting limits and communicating policy is a common part of student employees' responsibilities. Another important component of their experience was communicating with students to help them succeed in college. Bradley stated that he viewed his role as helping his 35 students succeed academically:

Also I think equally important is community building... it's a group of people who are together for an entire year and who will at least be on campus for most likely four years together, so I think that's as important as all the academic stuff we do.

He understood his role as dual purpose: helping individuals succeed academically and getting students connected to each other at the university. Similarly, Rick said, My job is rewarding — it's - you don't have to wonder, you know, what's the value of what you're doing-you see it very clearly. You're trying to be an advocate for education and you're trying to make a positive difference in these students' lives.

Rick also stated, “I don't see my role as small. I might be one of many mentors, but I think that the work we do together is really significant." He valued the role he had communicating with students to help ease their path through school. 
Participants also reported feeling like the information conduit between their departments and the students. Ethan felt that he contributed to his department by interacting with his students,

I feel like I'm the first impression that students get about housing and res life since I do live with them on a day-to-day basis... I make sure that our programming and our student development that we're doing in the halls are in line with the mission of housing and the missing of the university.

His role was to communicate, both verbally and through programming, the missions that guide his department. Gail echoed this idea, but took it a step further to include educating students:

The way I perceive it is that this is the student health clinic. We're essentially educating these students and arming them with the kind of information and patient know-how to kind of like then go into other kinds of health care offices and make important decisions and ask the right questions... I get to sit at that front desk and be an educational piece of that student's healthcare experience.

Gail's communication with students could be stressful, because she frequently fielded calls from students upset about paying the mandatory health insurance fee. It is pretty challenging to... communicate in a way that is not going to raise their defenses... and create an opening for them to see ways they can take advantage of this thing they don't want but are mandated to have... every time I have one of those conversations, I learn something from that person. 
Gail saw herself as furthering her department's mission to educate students about healthcare. She said that this makes her "feel like a valuable part of the university community." Even though the conversations with students could be difficult, they were a rewarding part of her employment experience.

Anne also had to manage difficult conversations with students. When some of her students misunderstood her motivations for documenting their violation of a policy, she had to "just smile and say "hey" to them, and keep a positive attitude. She added, "I definitely have a lot tougher skin than I did freshman year!” It was important that she continued to treat them the way she treated all of her other residents. Anne, Gail, Ethan, and other students reported that they served as a welcoming face of their department to students, serving as an accessible information conduit to their departments.

Participants reported communicating with students to share information that students need as well as to help mold college students' experiences on behalf of the university. Nearly all of the participants in this study reported that their primary job was to communicate with students.

\section{Faculty, Staff, and Administrators}

The second largest group of individuals with whom student workers reported communicating included faculty, staff, and administrators. Participants were frequently trained in part by faculty or administrators from departments outside the one in which they worked. They reported working with faculty and administrators as referral agents 
and collaborators in their work with students. Chris reported that the departmental training involved a lot of campus resources outside his department.

They like to pull in other departments... show off what the other departments can do, how we can work together, so if we have someone come in and they have an issue, we can send them to the right place to get their problem resolved. We were put in groups with the Queer Resource Center, and the Student Health Center and the Women's Resource center.

Understanding campus resources is an important part of training for students working in campus recreation, and students expected to work with staff from these departments get to know these professionals through training.

Ethan discussed not only training with administrators and staff from other departments, but working with them as well. Through the course of doing his job he said, "I communicate with other RAs a lot, pro staff within the department (housing and res life), and departments like the QRC, the Student Health Center and campus safetyhuge." Participants were frequently called upon to communicate with faculty, staff and administrators either through the course of their jobs, through training, or through supervision.

Some positions required workers to engage in activities that involved their working with faculty and staff members from other campus departments as well as from the department in which they work. Two students reported serving on committees as part of their roles. Jason said, "We try to arrange for each ambassador to work on at least one 
project that (contributes to) improving the university... we get to sit on the different hiring committees and make our recommendation as students." Quinn mentioned meeting with an assessment professional on campus to get help assessing a program he was implementing in his job. Rick said that in his role, he worked closely with a faculty partner for the class he mentors. "We're required to meet with them for an hour each week to discuss what's happening in the mentor session, the class, and what's working for the students - and any issues that may arise." For all three, meeting with faculty and administrators was part of their regular duties.

Students were sometimes called upon to represent their department in discussions with other departments to solve problems. For example, the participants from Campus Recreation reported that they are among the contacts that the Athletics department interacts with in cases of scheduling conflicts between student recreation clubs or intramural teams and the department of Athletics. "Sometimes there are issues with Athletics and the field, because we both share the field - so sometimes we mediate that," said Jack. In these cases, student front line staff members worked through these problems with administrators from departments that were not their own.

Students were called upon to present work to faculty and staff from other units on campus. Quinn mentioned that he was sought out after giving one of these presentations, "there were definitely professors that were approaching me and saying, 'that was really nifty what you did. How can I help? Or what can I do?'” Part of his work entailed communicating with faculty to train them about his functional area. 
In addition to the work-related conversations students had with faculty and administrators through their work, they also sometimes got to know these staff members on a more personal level. Bradley talked about the faculty partner with whom he worked: She's an artist and knows a lot about art... so we talked about art a lot. Just like, after we're finished talking about everything else — class business—we chat about that... we chat about life and what we've been up to.

The weekly meetings peer mentors have with their faculty partners included guidance and joint problem solving for the classes on which they collaborate. This also gave the opportunity for students in this role to enjoy relationships with faculty members on a personal level.

Graham said that he had a lot of personal conversations with administrators through his job. The conversations varied based on the person he was talking to, "if I'm dating someone there are some senior staff members I may make a comment about that to, and others I wouldn't." Graham identified that he had time to connect with administrators individually and have informal conversations through his work that resulted in personal connections.

Communicating with faculty, staff, and administrators was a common part of students' employment experiences. These professionals were supervisors, partners, and referral entities for the student employees. Additionally, since students sometimes worked in tandem with these groups of people, casual conversations were commonly part of their workday. 


\section{External Entities}

Some of the student employees reported communicating with off-campus entities. This category was composed of parents of other students, donors to the university and other "VIPs," and community resource providers such as the police department or ambulance services. The nature of the information shared varied significantly (and logically) based on whom the off-campus entity was: when communicating with parents, student workers shared information about university policies, procedures and resources. Gail said, "we communicate with parents a lot—who are either concerned about their child as a patient, or you know, they're a prospective student and what they're going to be able to access." Graham said he got calls from "parents who haven't heard from their child in a week - they're stressing out and they want to know what their child is up to and where their child is - this is not necessarily information I can give out." Both Gail and Graham had conversations with people outside the university community that they had to be specifically trained for as due to privacy laws regarding college students and health care.

When communicating with donors and VIPs, students discussed their lives and what it was like being a student at their university. This was part of Jason's regular responsibilities: "we go to talk to donors and tell them because of you, we have students who receive scholarships, who can stay in school... we talk about our experience as students." These students were not only communicating with donors, they were engaging in reflection about their lives as students through the course of their jobs, as well. 
Communication with off-campus emergency services was also mentioned by the Resident Assistants. In crisis situations the RAs interacted with local police and ambulance officials. Describing a stressful situation at work, an RA described a night on call where he had one student arrested and another medically transported in the same oncall shift. Ethan said "In [this city's] community—not as much as the [campus] community_I've communicated with [city] police a few times, county ambulance people a few times. I'm sure there will be more - this year hasn't even started yet!" Communicating with external entities was an important part of crisis management work for some student workers.

All of the participants reported that they worked with off-campus entities at one time or another through their positions. The nature of the positions determined who the off-campus entities were, and they included local emergency services, human services, parents, alumni, and donors to the institution.

\section{Summary of the Communication Theme}

Throughout the interviews, all of the participants in this study reported that the primary function they served in their jobs was to communicate. They did this most often with other students, but they also communicated with colleagues, faculty and administrators, and off-campus entities as part of their jobs. Their jobs were to communicate, but their jobs also put them in positions in which they talked about a variety of subjects unrelated to job duties. 
Students in this study reported that their employment did not limit the time they spent interacting with faculty and other students. Instead, this kind of communication was their job. Students in this study report that they are able to engage with their peers and other students extensively through their positions.

Students in this study engaged in conversations with students and faculty members in a variety of ways, in situations that were both structured and unstructured, and both purposeful and casual. Students who worked as Peer Mentors had weekly, purposeful conversations with a faculty member as they worked together to educate, guide, and support the students they worked with. Some of the participants also talked with off-campus entities as part of their jobs, including donors and other VIPs, and service providers such as fire, ambulance, and local police officers.

\section{Peer Colleagues}

Participants generally reported a high level of interaction with their peers on the job. Some positions required students to work as part of teams that were intentionally developed, and others situated students working in proximity to one another, thus enabling conversations to happen. Peer interactions happened in three ways: as part of regular work responsibilities, in relationship building, and in leadership roles (for example, returning staff members trained or role modeled work for incoming student workers). 


\section{Regular Work Responsibilities}

Students' regular work responsibilities required them to interact with their peers (other student staff colleagues) both formally and informally. Student colleagues met in staff meetings, sometimes worked in teams, and sometimes relied on each other for assistance. Jason reported that individuals don't make decisions - that "a lot of the time, it's the whole group that makes the decisions together." Individuals bring up topics and the group discusses them "and then we move forward. I don't think I've ever brought a decision on my own.” Quinn talked about working with his colleagues to pull a successful program together: "Everybody was sort of working in their own little pods... I presented to the group and started designating people, like, I need you to do this...I sort of took over... for a week or two." Formal working arrangements enabled students to get more done and manage larger processes by forming teams that were both established for the year and ad hoc.

Students also interacted with their colleagues informally. Participants reported that down time at work enabled plenty of casual conversations. The topic of conversation ranged from academics, university policy, and scholarly theories about the kind of work they do, to gossip, internet memes and relationships. Chris said, "You know how we are. [People who live in this city] love to talk about the weather." Quinn reported a lot of camaraderie in his work place as well: "we are geeks and dorks, so we talk about cartoons, computer games... we also talk about social theory, which relates to work... we talk about so many things." Graham affirmed that through his work, "I've met a lot of 
very interesting people and made some good friendships.” This informal rapport building made the work environment more welcoming and fun for the employees.

Interacting with peer colleagues was not always an easy, comfortable experience.

Participants reported friction in those communications as well as they came to know their fellow staff members. Jason commented,

There was a lot of miscommunication... I didn't know what was going on and I didn't want to share that with anybody because the culture I grew up with, it's not ok... but now, I'm learning more and more how to tell people, ok, I understand where you're coming from, but this is my idea, can we talk more about it and find a way we can both be happy and our team is happy?

Jason had to learn how to communicate better with his colleagues to work as a part of that team.

Quinn discussed how he had to work with the other student employees in his department to change the culture of their services. "Queer students of color reported not feeling safe accessing the QRC, saying it seemed designed for "primarily white traditional-aged students. So my job was not only to create a safe space but also promote this safe space as well." He continued, “As someone who occupies sort of intersectional spaces and marginalized spaces, I know what it feels like to not really have your concerns for your needs taken care of." He had to work closely with his peer colleagues to create a more inclusive approach for people of color in their space and their programming. 
Occurring both formally and informally, interaction with peers and colleges was a large part of students' work expectations and process. Students collaborated on projects, assisted each other in their work, and learned together through formal training. They also enjoyed down time to get to know each other personally and build friendships.

\section{Relationship Building}

Several of the students engaged in teambuilding activities as a part of their jobs. It was deemed important to the nature of their work that students connected with their peers and form bonds characterized by trust and good communication. Student positions included in this category are Resident Assistants (RAs) and campus recreation employees; both of these positions have a good deal of responsibility for overseeing the activities of other students. Anne said that was part of the reason why so much team development was done during their training, "If you're on call, and you get a call about something, you usually need to call backup.” Since RAs typically get calls for emergencies in buildings or communities that are not their own, they contact the RA who lives in the area where the emergency is occurring for backup. Additionally, campus recreation employees reported intentional relationship building as part of their annual training. According to Rick,

It's the one time that everyone gets to come together to meet each other and figure out who's doing what and how we can help each other. It's cool, so when the shit does hit the fan and you're yelling over the radio for help, it's nice to know who's on the other end. 
Creating an environment in which student employees know and can trust each other in a crisis is important to staff members who work in jobs in which they need to handle difficult situations. It also has other benefits as well. Rick felt a sense of connection to the campus through his job. "I don't feel lost, and with the mentoring community, I feel very connected to the campus." Connections built for doing the job have implications for Rick outside his workplace.

Jason talked about working as a team to uphold the integrity of the program. As a student leader in an organization, it's bad to mess up, but, "In the ambassadors, it's the entire program that pays for it" when you mess up. He and his peers came to understand that they needed to rely on each other to uphold the standards of the program.

Participants reported the need to work on teams with their peer colleagues. Formal and informal relationship building helped them work together more effectively through the course of their regular responsibilities, which helped them feel more confident and empowered when doing their jobs.

\section{Leadership}

As returning employees, students were also called upon to engage in leadership with their newer colleagues. Most respondents reported being trained, at least in part, by returning staff members in their same position, and then in turn being responsible for training the next incoming staff members.

Jason reported learning from quite a bit about mingling and networking from his more experienced peers. "I'm so terrible at it... but I have made a lot of good friends in 
the program and they always try to bring me out... and they also help me practice a lot about how to mingle with people." He said that after two years, he wanted to talk to everyone because he felt "so confident, so comfortable." He valued the informal learning and support he received from his more seasoned colleagues.

Some students were put in the position of determining the kinds of staff development new student staff would receive, as well. Jason said that part of the content of the training is determined by returning staff members.

The first year I was in the program, we invited someone from the school of business to do the DISC assessment, so that was really helpful. It's different every year and it depends on the coordinators, who they chose to invite to the training. Jason valued learning from his more experienced peers and he appreciated his ability to step into a leadership role within his organization as a returning staff member.

Bradley said that the peer mentors often present professional development workshops for the newer mentors. "I tried to go to as many workshops and events as I could... I thought they were all good programming." He went both to offer support and to learn from his peer colleagues.

Returning staff commonly trained new staff or acted as mentors to them. Having responsibility for other staff members caused participants to view their responsibilities differently and to think about their roles in terms of leadership and role modeling. They also discussed the need to show support for colleagues presenting training opportunities to others. 


\section{Summary of the Peer Colleagues Theme}

Participants reported that they were able to engage with their peer colleagues often and in meaningful ways through their jobs. They worked together on job tasks, supporting each other and sharing information. They engaged in formal (through training) and informal (through establishing friendships) relationship building through their jobs, and they also interacted through leadership opportunities as incoming staff members were trained by their more experienced peer colleagues.

\section{Relationship with Supervisor}

Relationships with supervisors were mentioned by all participants in this study, and the themes that emerged in coding described a varied experience that students had with their supervisors. Two students reported receiving no supervision in their work, and the other students discussed their supervisors in terms of support, learning, and friend/ mentor terms.

\section{No Supervisor}

Peer mentors mentioned that they did not feel that they had a supervisor, and that this was a positive aspect of their positions. Supervisors were not hanging over them all the time, evaluating them based on criteria they didn't understand. Lack of supervision gave them freedom and flexibility to do their jobs the way they saw fit. Rick reported that he didn't see the faculty partner he works with as a supervisor:

I think that's partially because a lot of the faculty members I've worked with at least, give me creative freedom to structure the ... mentor sessions how I want 
and they trust us to do the best to support the students. That trust sort of erodes that sort of authority... we see it more as a collaboration, a partnership than sort of an employee/ employer relationship.

Bradley echoed this sentiment. He assumed that the program coordinator would technically be his supervisor:

I chatted with her in the past here and there, but I've never really had one conversation with her. My own mentor position has gone really smoothly and there's never really been a need to communicate with my supervisor, but I guess it would be her.

The two peer mentors interviewed both felt that they did not have a supervisor in their roles, but they both reported meeting weekly with a faculty partner, with whom they troubleshot problems and created a plan for their mentor sessions. They credited this lack of outside control over their work with their ability to enjoy a lot of autonomy in their positions to use methods they felt best when working with students.

The peer mentors in this study felt they worked as peers with their faculty members. Though they met with the faculty weekly, they felt a sense of freedom to carry out their responsibilities in their own way, without being directed by a supervisor, and this freedom was viewed positively.

\section{Support}

Overwhelmingly, students felt supported by their supervisors. Students went to their supervisors with concerns about work, colleagues, academics, family, and their 
career goals. Jason said, “Even when I'm feeling vulnerable, he's the person I can feel like comfortable enough to go talk to... he's always the person that I feel like I can go and connect with... he's so supportive." Graham commented on how his boss advocated for him when their department was merging with another. By arguing about the value of this student as an employee, the supervisor was successfully able to maintain a position for the student through the transition.

Another student received support from his supervisor when he was having trouble navigating the dynamics of a staff team. He had difficulty "working with a group of people that had so different concept of what leadership is like and what being a student is like, and what being part of the group is like," and his supervisor was a very supportive presence as he struggled to make sense of these cultural differences.

Gail's supervisor was also a caring presence. Her supervisor was a "kind of supportive figure when it comes to schooling and life, like if I'm having trouble in my romantic relationship, she's really open to me, like... 'you can always talk to me-I'm here to listen." Quinn echoed this, saying, his supervisor "is also about honoring your full self and your whole self at work, and so if I just broke up with somebody, or somebody just died, or there was something pulling me away from work, she'd want to know" and would help him rearrange his schedule and manage his workload through times of personal hardship.

Supervisors were also encouraging to their employees. Students were told about new, better job opportunities on campus, and were recommended for hire by their 
supervisors: Jason said that his previous boss told him "you'd be great for this awesome group on campus called student ambassadors... she sent me the web site and she nominated me as well." This encouragement meant a great deal to the students who discussed it.

Some students also benefitted from receiving help with cover letters and resumes, and several supervisors also provided letters of reference. Chris stated that his supervisor was a great help to him landing his first job after graduation, "he helped me tighten my resume and helped my cover letter. He ran a mock interview with me before I went to my real interview." Because of his supervisor's efforts, he felt very prepared when he went into that interview. He did well and got the job.

The students in this study reported feeling supported by their supervisor or their main supervisory figure or partner (in the case of the peer mentors). They benefitted from good advice, encouragement, and increased access to resources and knowledge because of those relationships.

\section{Learning}

Students reported learning from their supervisors, both informally through constructive feedback and formally through training. It is important to note that supervisors' supportiveness impacted the learning of their employees. In the interviews, supervisors were often described as being supportive when students made mistakes. Graham reported appreciating his supervisor "when I goof up, he's compassionate about 
that and tells me what I've done wrong in a way that doesn't make me feel shamed and lets me know that it was wrong and how to change it in the future."

Jake discussed a time he had a problem with his schedule and tried to cover the problem himself.

It ended up not working out real well. So we had this little meeting, so basically they were like, look: even if you are going to be late and it's a last minute thing, don't feel like there's pressure on like you're going to lose your job. They're like, let us know. We'll figure it out... that was kind of an eye opening experience. On a lot of other jobs, if you're late and you don't call or something... that could be really bad. Here its like, it's bad, but we'll figure it out-we'll work it out.

This kind of developmental, supportive approach to addressing behavioral problems led Jason to talk specifically about appreciating his supervisor's supportiveness when he made mistakes, "He always tells me that if you never make any mistakes, you never learn-you never grow." Jason valued his supervisor's role in helping him develop as a future professional.

Formal training was also important to students' positions, and was typically led by supervisors. Jason reported, "We learned to eat properly because we go to a lot of fancy dinners." Bradley described how peer mentors went through trainings on creating lesson plans and leading discussions and also were trained on the daily functions of the peer mentors. Chris was led through a mock interview process to prepare for application for a post-college job. Both RAs and campus recreation staff reported going through 
trainings on policies and procedures and how to mediate conflicts and other tough situations, and the campus recreation staff also became CPR certified. According to Jack, "we do have a daylong first aid class we go to. It's like 9 to 5, and we get our certification in first aid and CPR." Chris stated that "They really push leadership development, not only for us but how to portray that to the rest of campus... there's always something new to learn in leadership, and everyone has a different perspective in that, so I find that fascinating." Formal training programs were important parts of the supervisor-employee experience for these participants.

Students reported formal learning happened with supervisors as well as informal learning achieved through supervision. In discussions about training, supervisors were mentioned almost without fail as the primary source of training and information about the position. Students received training on topics ranging from campus resources and policies and procedures to crisis intervention and how to plan events.

\section{Friend/ Mentor}

Several students identified their supervisors as being mentors and "like a friend." They described their feelings about the friendship and mentorship aspects of their relationships with their supervisors differently. Quinn reported, "I feel really lucky that I have a supervisor but we are also friends. We keep it professional, there's not a lot of talking outside of work, but yeah, there is very much a friend dynamic. I think its respect as colleagues as well." His supervisor was a friend of a friend, which was how he learned of the department in the first place. 
Gail also valued her supervisor in a similar fashion. "There's definitely the work aspect as a manager..., but she's also a good guidance/ mentor/ kind of supportive figure when it comes to schooling and life." Jason took this further,

I feel like he's my supervisor, but we have that friend and mentor kind of relationship, that I respect him so much... it will be different because I am graduating, but I kind of feel that way about him that he's always going to be my mentor, just there and encouraging me and really supporting me when I make a mistake.

Jason gives a lot of credit to his supervisor for helping him through an emotional learning curve within his job. He mentioned the support and mentorship of his supervisor on a couple of occasions, saying that the relationship was important to his ability to manage school and work.

Jason also received support from his supervisor in the area of his professional growth trajectory. Jason told his supervisor he liked working with students and wanted to go into the field of Student Affairs, and his supervisor "said, 'this is a program called NASPA. You're going to love it,' and literally the next week, he signed me up for the conference, and I was like, 'this is awesome! I love it!'” He said that his supervisor also made sure he was connected, "as a student ambassador, I get to know almost everyone who works in student affairs on my campus... the networking piece is just amazing." Jason's supervisor nominated him for a national award, as well. Jason said he valued "having a great supervisor-helping me find out what I want, and having all those people 
support me to go and get what I want for my future." Jason was very appreciative of his supervisor's work to help him along his career path through his on-campus position. Jake echoed this:

Your supervisors will come to you and be like, hey, you've been here enough, you've put in your time, we want you to do this job. And so that's really niceespecially when you get told by your supervisor that you should apply for this job that I'm interviewing and hiring for.

Some students referred to their supervisors as mentors, people who guided them through their positions, helping them focus their experiences toward their future goals. Some spoke of their supervisors caring for them on a personal level, making sure their needs were met and that they were doing all right. One thing is clear: students overwhelmingly felt that their supervisors cared about them and wanted them to succeed beyond the job, not just within it.

\section{Summary of Relationship with Supervisor Theme}

Two of the participants reported that they had no supervision: in their view, this was positive because they felt that they had a sense of freedom to exercise their creativity and do their work the way they saw fit. The professionals with whom they had weekly contact through the course of their jobs helped them guide the work they did, and that relationship felt like a partnership to them. However, unlike the other participants, they did not report a strong sense of supportiveness in their work environment. 
For the other respondents, supervisors' supportive approach to managing behavioral issues helped students recognize their value to the staff team, and strengthened a relationship of respect and trust. Furthermore, students who identified that they had a supervisor felt positive about that person. They reported learning from them through supervision and evaluation. Most felt they had a friend and a mentor, and they felt supported and connected to the university through the relationship with their supervisor. Participants felt more integrated into the university through the relationships they cultivated with their supervisors.

\section{Academic Connection}

As the themes emerged, the area of academics quickly became evident in its importance to students. Participants in this study are students, so the conversations about school were unsurprising. Additionally, the fact that students spoke both positively and negatively about the interface between school and work is to be expected. What is interesting is the range of experience between the two lenses or subthemes of Interference and Integration.

\section{Interference}

Balancing academics with employment was not always easy for participants. Students frequently reported difficulty finding time to study because of their work commitments. Anne discussed the importance of scheduling in a special time and location for study: 
It's a little more difficult because in your room... you can have residents come up to your door, interrupting that, and even in the library, you can see anyone pretty much anywhere, so it's hard to find a good quiet place.

Because finding a good place was difficult and because her job is demanding, Gail had to put effort into identifying chunks of time she could devote to studying.

A couple of respondents reported studying less, and these students also reported having a difficult time maintaining their GPAs. Jason reported,

I spent a lot of time on how to make the program better and forgot to make my GPA better. I just feel like... I need to focus on my study and school and really do my work at school, but the support is not there.

For Jason, the focus on work eclipsed his focus on academics for a time, and he expressed frustration at tutors and study hours devoted for students involved in athletics but not for student employees. Quinn's story was similar. When he was planning a major event he noted that, "definitely what started to suffer was my grades." Their academic focus was challenged by the addition of jobs into their schedules.

Interestingly, a couple of the respondents also mentioned feelings of frustration that classes interfered with the work they were doing on campus. Quinn said, "I'm doing the work that most people go to school to do. I'm doing that. So why am I in this class? Why am I in this introductory level class...where it was like, I'm doing this already at work." Quinn and the other students who made similar comments viewed the work they did as very important, and the need to be taken seriously as employees as important as 
well. The students who commented about their jobs interfering with their academics also reported growing in the areas that they initially found difficult to manage, developing skills related to time and stress management and prioritization.

\section{Integration}

Whereas there were definitely some negatives stated regarding academics and student employment, there were also positive relationships between the two. Rusty shared that his job on campus made school seem even more important to him. "I wasn't as involved in the activities (before this job); I was just focused on the school work. So now I'm involved in schoolwork and the campus as well."Quinn felt similarly: I really enjoy going to school. You know, what's great about being proficient and competent in my job and also competent in my studies is that I get to challenge myself-like I have to do a lot of self directed challenge.

He discussed taking classes outside his major that he thinks will help him attain his future career goals. He has done organizing work before and hopes to continue in the nonprofit sector when he graduates, doing very similar work. He said:

I feel like [this institution] was where I wanted to be... [my school] is much more academically involved (than the community college in which he began his studies). People are like, 'I'm here to go to school,' and so you have very studious people that are here. 
Quinn valued the environment where he worked because of the level of intellectual engagement he had with his peers, and his ability to integrate his work, school, and longer term goals.

Nearly all of the respondents reported talking to colleagues, supervisors, and others about their academics. Many of the students were able to study at work. Rusty said,

Sometimes if it's a shift that isn't very busy, usually the closing shift, I do have time to work on homework-I can't be so engrossed in it that someone asks me a question and I'm not paying attention... but it has helped me work on schoolwork as well as help students at the same time.

Jake had a similar experience, "if there's two of us, we can do homework and one of us will be working" for part of the shift. Students in this study demonstrated flexibility in maximizing their opportunities for studying finding the time in small pieces throughout their day.

Students were also able to hone skills that made all aspects of being a student easier, such as time management, prioritization, and organization. Rusty reported that his job made him more organized. Quinn learned to better manage his time. Discussing what was difficult, he mentioned both time management and prioritizing. "Managing your time-being a working student was really difficult" and prioritize, "it was me saying 'I'm sorry, I don't have time to get this done because I have to work on classes this week." 
Because his job responsibilities varied based on the projects he was working on, managing his time carefully became very important.

Jake shared an experience with other students he works with, saying, "A couple of the guys I know are English majors so we BS about that, talking about professors we've taken classes with." His position offered him the opportunity to connect with his fellow students about their academic lives as well as their work and social lives.

Finally, only one student reported congruence and a direct relationship between her field of study and her work. Gail is studying in preparation for a career in alternative medicine, and appreciates the ability to work in the healthcare field, "continuing to work in the industry, I feel like I'm networking and making connections in the industry." While she was more interested in alternative or nonwestern medicine, she valued her ability to engage with her colleagues and supervisors about what she was learning in the classroom and differences she saw between her studies and a more traditional, western approach, as well: "I kind of am watching a lot of the pitfalls that I would like to address in my later career." It's not a drawback of the job; instead, "I don't think it's a drawback, because I think I do value having the experience to know that it's a reality and to know how that reality plays out for people day after day." She added:

Conventional health care, which is sometimes hard to-hard to watch... I studied community health education but I'm particularly interested in home health care and alternative medicine, so to be working in actual medicine I kind of am 
watching a lot of the pitfalls that I would like to address in my later career...I do value (knowing) how that reality plays out for people day after day.

Her ability to see the relationship between her studies, her work, and her career aspirations make even the difficult parts of her job easier to navigate.

Students reported that generally, their positions either worked with their academics or that working on campus helped them take advantage of opportunities to slip studying into their schedules. Problems with organization, prioritization, and time management were also reframed as learning opportunities, and students reported that they were able to learn more skills in those areas that helped them in their academics and would be useful the rest of their lives.

\section{Summary of Academics Theme}

Students reported that their positions both helped and hindered their ability to achieve academic goals. Grades slipped as students adapted their schedules and adopted better time management techniques to accommodate increasing demands on their time.

Although students reported struggling with academics and sometimes saw negative ramifications of their positions play out through their grades, they more frequently reported that their positions aligned with and supported their academics and their long term goals. The points of interference between academics and their jobs were also cited as growth opportunities: difficulty prioritizing work led to increased focus and development in their time management capabilities. 
Students realized several benefits from their positions. One student enjoyed congruence between her studies and her career trajectory. Another reported that working made school feel more important to him, and another discussed how some of his peer colleagues shared the same major, and they shared informal conversations at work about classes and teachers. Students found opportunities to study at work and learned how to better manage their time and energy related to balancing work and school. They engaged in conversations with peers and supervisors about academics.

\section{On-Campus Activity}

In the interviews, participants were asked to comment on the ways in which the way they spent their time was affected by their jobs on campus. Prompts were given to help focus the conversation, and one of the prompts was "campus events." The themes that emerged included information about students' involvement with on-campus events, but they also included many references to the kinds of campus resources that students were aware of, and therefore able to utilize, because of their positions.

\section{Attendance at Campus Events}

Students almost unanimously reported not attending programs and events on campus, unless they were specifically related to their positions. RAs and Ambassadors both reported that attending events was part of their job. Anne reported that she loved this part of her job: “me personally, I just like to go because I'm a huge school pride person. Football games and the dive-in movies are always fun... with those campus events, it helps make residence life feel a little more traditional—makes it a little more fun." Rick 
said, "The cool thing about mentoring is you're always trying to find out about cool events to get your students to go to, so yeah, that helps us with that form of engagement with the campus." Whereas these students did not report attending more events in their free time because of their on-campus jobs, they reported that they enjoyed the part of their job that involved bringing the students for whom they were responsible to events.

Students mentioned that they felt that their job was their involvement on campus; they felt a lot of connection to and sense of ownership of the campus because of their jobs. Jason reported that being an ambassador, attending events was an expectation of his job. "I do go to campus events. I never went to one before I was an ambassador... I didn't know there was so much going on campus, and yeah-I do now!" This was echoed by Quinn, "I feel lucky and special that I get to be a part of the community and do this sort of (community building) stuff." Quinn added:

I'm also less likely to do things for free... I think that for me, that I'm not going to engage in volunteer work - because a lot of people do volunteer work at this job, it's something they care about and the volunteers get it out of their system to just feel connected, as part of something. Well, I do a job where I feel connected and part of something all the time.

Similarly, Ethan, said, "I have fun with programming a lot, just getting to know other people I wouldn't get to know if I wasn't an RA.” Student involvement is traditionally viewed as excluding student employment, but students in this study reported finding similarities between working and being involved in campus in other ways. 
Students also felt tired both working and studying on campus; they reported the need to take a break from campus to seek some balance in their lives. Anne said that being an RA has definitely influenced how she spends her time, "I take advantage of those days when I'm not on call. Especially those weekends-because when you're on call, you have to stay within 15 minutes of campus...on free weekends, I go off campus." Quinn talked about his need to take a break from work and school periodically. After a very stressful, unhealthy experience, he says he learned that he is "perfectly allowed to have something where I can just decompress on the weekend and watch really stupid comedy on TV and sort of turn off my brain a little," and attending campus events would not fill that need. He viewed campus events as analogous to the work he was doing already.

Jason is using his experience to mentor his younger brother, who just went to college.

I tell him, “it's great you're going to college, it's great you're going to do well in class, but don't forget the other things you're going to learn in life while in college because you may never have another chance to learn that after college. So go join different organizations. Join different clubs. Get to know those people!" Jason views himself as being engaged on campus through his job, and values this part of his experience.

Overall, students did not report that their employment on campus influenced them to spend more of their personal time attending campus events. Instead, the students who 
attended campus events through the course of their jobs reported that they enjoyed that aspect of their employment.

\section{Utilization of Campus Resources}

Another aspect to the on-campus activity theme was students' reporting of their utilization of campus resources. Students reported being trained about campus resources and networked into the system of student support so that they could be referral points for the students they serve through their jobs, and this had a positive impact on their own ability to access these resources.

Rusty mentioned that because he had been trained on the location of offices around campus and what they do, he was more easily able to navigate applying for graduate school, "It's time to go to the graduate studies office-I know where that is." When it came time to apply, finding the office to get questions answered was easy.

Three of the participants mentioned taking advantage of the Student Health center for stress management and other needs. One participant said, "I crashed of course, two months after my job started.” He described seeing a counselor who helped him work through managing his stress and his time better. Although his role contributed to his excessive stress, it contributed in a positive way as well because he had been trained about the student health center and the services offered there.

Chris mentioned that he used a host of campus resources after learning about them during training for his job. He said, 
I've definitely learned a lot more about the different organizations on campus and what they do. I now take naps every now and then in the WRC - they have lots of really comfy couches, and I've used the Disability Resource Center now, when I broke my thumb, so all those things I didn't know were available —-I still have my taxes done by [an on-campus service] every year, which is really helpful.

Further, Chris summarized his experience this way: "If it wasn't for campus rec, I wouldn't have spent as much time on campus and built the relationships that I have." Whereas his training about campus resources was designed to help him assist students in navigating the university, he benefitted from the knowledge personally as well.

Jack also credits his role with connecting him to the campus:

Everything I have here at [my institution], even the people I've met outside campus rec, it's somehow related to campus rec, I feel like. Just being on campus all the time, being in that building, meeting people...it's been good.

Most of the participants had received training about the resources available on campus because they were expected to be referral agents for other students. They also related that because they were more aware of campus resources, their own navigation of the university and use of resources was enhanced.

\section{Summary of On-Campus Activity Theme}

Participants in this study reported that they attended campus events primarily when it was required for their positions, and for many of them, attending events or facilitating them was part of the job. Students working within Campus Recreation 
obtained their jobs through involvement with their respective clubs, but overall, student employees interviewed here typically felt a connection to the university directly through their jobs, not through clubs or organizations they joined because of their positions.

This study also revealed that the students trained to serve as referral agents for other students reported using some of the resources they knew of themselves. Therefore, an added benefit to their job was increased knowledge of how to access support systems.

What is particularly compelling about student employees is that as a result of their jobs, students participating in this study also reported feeling very connected to campus because they felt like part of that same support system. Put another way, students in this study did not see themselves as consumers of programs offered to students; instead, the saw themselves as facilitators of programs for others to attend.

\section{Conclusion}

As participant interviews were coded, six important themes emerged in respondents' comments about their experiences of student employment. The themes of communication, relationships with peer colleagues, relationships with supervisors, academics, and activities on campus all emerged. All participants reported that the bulk of their jobs entailed communicating with students, faculty, staff and others. 


\section{CHAPTER 5: Discussion}

Ideally, all of a student's on-campus experiences would contribute to that student's learning and development. This study approaches student employment from the approach of on-campus work holding the potential for student development and academic and social integration. It seeks to understand what parts of working support or hinder student development, integration, and students' overall satisfaction with their college experience. Chapter 4 discussed the data that emerged from the data, and this chapter will answer the research questions and offer a discussion of the findings.

\section{Research Question 1: Student Development}

The first area this study attempted to understand was how on-campus student employment helped and/ or hindered students' development. Developing professional competence and growing personally were important areas that emerged in students' reflections on their experiences. Although there were no questions that specifically asked about the areas of learning and growth participants experienced through their work, codes such as organization, emotional growth, purpose, cultural differences, teamwork, and "I make the call" are clearly about development. Upon reviewing the literature related to student development, I found that the comments students made matched well to Chickering and Reisser's revised theory (1993) of student development.

Students commented on a variety of ways in which they developed both personally and professionally through their positions. This section explores the data 
revealed in the study using the framework of Chickering and Reisser's (1993) model of student development.

The seven vectors as they appear in this theory are developing competence, managing emotions, moving through autonomy toward interdependence, developing mature interpersonal relationships, establishing identity, developing purpose, and developing integrity. These vectors offer an effective framework for examining the professional and personal development that students reported experiencing through their positions. This section of the paper explores the evidence that student employees developed through their jobs on campus, using the vectors as a structure. Development in these areas occurred both formally through training, and informally through regular supervision.

\section{Developing Competence}

This vector is described as students' development of competence intellectually, interpersonally, and physically and/or manually (Chickering \& Reisser, 1993). The vector also considers students' development of confidence in their abilities in these areas.

Students in this study gave examples of how they were able to develop a good deal of competence through their on-campus jobs. Students experienced improvements in their ability to talk with others, their self-confidence, and their competence at specific tasks. Gail from the Health Center reported gaining a deeper understanding of conventional health care systems and being able to engage that understanding in classroom conversations about alternative health care. She was able to engage with 
students who weren’t happy about being required to purchase health insurance as well and reported, "I learn a lot every time I have one of those conversations." Because she is planning on entering the healthcare field, difficult conversations are seen as learning opportunities.

Interpersonally, Jason reported increased ability to engage in small talk conversation with people he didn't know. His peers "help me practice a lot about how to mingle with people." After being in the program for two years, however, he said, "you want to connect with people all the time, because you feel so confident, so comfortable!" Jason mentioned meeting a student in a similar role when applying for the job, hoping he could develop the same attributes.

Some of this practical competence was developed through trainings. Jason described dining etiquette as part of his training, Bradley discussed extensive training he received about how to create lesson plans, lead discussions with groups and manage the daily functions of mentorship. Participants reported being trained on policies and procedures, mediation and communication. Campus recreation staff also became first aid and CPR certified. Leadership development was also an important piece of training for some participants. This extensive training helped students develop competence in a variety of areas.

While what constituted practical competence differed between positions, training programs were a part of all students' employment experiences, and students all reported developing some kind of professional competence through them. Developing competence 
was also achieved through regular supervision and evaluation. Finally, developing competence was well represented in students' comments about their work: every participant reported becoming more professionally competent as a result of their jobs on campus.

\section{Managing Emotions}

The Managing Emotions vector is described as one in which students develop the ability to recognize and accept emotions, as well as to appropriately express and control them (Chickering \& Reisser, 1993). Students were able to grow in this vector in different ways. Rick developed emotionally by learning how to establish appropriate boundaries with his students, "what I've learned from some of the more experienced faculty members, they teach you to care about your students and look to promote (students') success, but don't become so emotionally invested in them that you neglect your own well being." Developing and sustaining healthy emotional boundaries with students helped Rick develop, and moved him through the managing emotions vector.

Anne had a negative experience that caused her to do some close reflection and growing in the area of her emotional response. When she was wrongly accused of having negative motivations in documenting some of her students for a policy violation, she says "I shut down — it's hard to keep that positive attitude...I didn't want to act differently towards them, so I had to just smile and say, 'hey."” She says she went into a reflective mode and it took her a while to process through her feelings about the situation and learn from them. 
Students spoke about encountering situations that prompted them to have negative emotions through their jobs. They learned how to work through frustration and hurt, and they learned to care about the students with whom they worked through establishing healthy boundaries. Those situations became personal development opportunities as participants learned more about how to deal with and manage negative emotions through their jobs.

\section{Moving Through Autonomy Toward Interdependence}

Students in this vector are said to develop increased emotional independence, selfdirection, problem solving ability, and persistence, as well as recognition and acceptance of the importance of interdependence (Chickering \& Reisser, 1993). Within this vector, students grow in their ability to manage their own affairs, solve problems and make decisions.

Jason told a story about his personal development that cut across multiple vectors, and that story has to do with the way he communicates with his staff team. He is from Taiwan and is the elder of two boys in his family. The way he was raised gave him the perception that his opinion was always right, but at the same time, it imbued him with a sense of it not being okay to speak up when he was wronged. When his ideas were not immediately adopted, he felt wronged and as a result, "There was a lot of miscommunication...but now, I'm learning more and more how to tell people, ok...can we talk more about it and find a way we can both be happy and our team is happy?" Jason had to learn to communicate better to become part of a healthy functioning team. 
His story related to both the Moving Through Autonomy to Interdependence vector and the Establishing Identity vector discussed below.

Jake also learned about operating better as a teammate when he tried to cover for a scheduling mistake on his own. By trying to deal with the issue without help from his supervisors or his teammates, problems arose. In the subsequent learning moment, he reports being told by his supervisors, "'Let us know, we'll figure it out, because a lot of people we work with live on campus, so they can contact somebody else'... that was a pretty eye opening experience." Through this experience, he learned both about his place on a larger team of individuals and about the supportiveness of that team.

Learning how to troubleshoot problems, make decisions, and act as a responsible member of the team are ways students developed along this vector through their jobs. This area was more frequently included in the comments of students who had the opportunities to work on teams in their roles, as well as students who experienced more autonomy in their positions.

\section{Developing Mature Interpersonal Relationships}

Tasks in the Developing Mature Interpersonal Relationships vector include the development of acceptance and appreciation of differences as well as the capacity for healthy and lasting relationships (Chickering \& Reisser, 1993). "Students' interactions with peers provide powerful learning experiences and help shape the emerging sense of self” (Pascarella \& Terenzini, 2005, p. 22). This is an important vector in which student employees reported experiences that helped them develop. 
Jake related an experience that indicates he may have undergone some development in this vector. One of the tougher parts of his job was enforcing policies that he doesn't necessarily understand or see as very important. One such policy was the policy prohibiting taking photos at intramural games and he was uncomfortable confronting a female student wearing a hijab, “I don't want to come across like I'm singling this person out, but nonetheless, I go up to her and tell her she can't take photos." This interaction caused Jake to evaluate his job and doing the right thing, weighing his need to ensure a welcoming space for students with a desire to demonstrate fairness in upholding the policy.

Quinn discussed his role as infusing intersectionality into his department. Queer students of color reported not feeling safe accessing the QRC, saying it seemed to be set up for white students. He said, "As someone who occupies sort of intersectional spaces and marginalized spaces, I know what it feels like to not really have your concerns for your needs taken care of." He uses this experience in his position on campus to help make safer spaces on campus for other students who identify as in the intersections of race, gender, and sexuality.

In their roles, students were called upon to create and uphold healthy and inclusive on-campus environments for their students. This included communicating in supportive ways across differences, and it also certainly included building connections with colleagues based on respect and trust. Working with people different from them to 
uphold policy and facilitate programming were two ways students reported working through this vector.

\section{Developing Purpose}

In this vector, students develop clear vocational goals and commit to specific interests and activities (Chickering \& Reisser, 1993). They also establish interpersonal commitments. This vector was well represented in students' comments. Several students mentioned the relationship their jobs had to their career goals that were unrelated to their majors. They drew connections between the skills they were developing in their positions and those they would need in their future careers.

Jason stated that he told his supervisor that he wanted to go into Student Affairs, and his supervisor immediately told him about NASPA and got him registered for a national conference. One of the main benefits of his job was:

I want to go into student affairs. The biggest benefit is definitely recognition of people in this area, or in the industry... as a student ambassador, I get to know almost everyone who works in student affairs on my campus... the networking piece is just amazing.

Jason learned about student affairs as a career on his job, and was also able to explore the field through his work. He valued the connection between his job and his career goals.

Ethan said that he felt a career in a medicine was his calling. "I think my various experiences, such as being an RA, dealing with people on all sorts of levels to kind of help someone who is in need has helped me figure that out." He didn't discover his 
purpose through his work on campus, but his work helped confirm his desire to go into medicine, because working with people who needed help resonated with him.

Gail remarked that her job helped strengthen her commitment to her chosen career, because the position involved "Conventional health care... I kind of am watching a lot of the pitfalls that I would like to address in my later career." She said it's interesting that she is able to work within the system to help students learn how to navigate it and make smart health decisions while simultaneously learning to critique from a holistic healing perspective.

Several participants reported that their development of purpose was influenced by their roles working on campus. Students were able to see the connections between their jobs on campus and their future careers, and they felt their jobs helped them along that trajectory.

\section{Developing Integrity}

The Developing Integrity vector is described as one in which students' transition from rigid, moralistic thinking to a more individualized, personal value system that respects the beliefs of others (Chickering \& Reisser, 1993). Students' values and actions become increasingly congruent as they move through this vector.

Ethan said that every time he worked, he made decisions about how to address student behavior. His training prepared him generally for this responsibility: 
I make the call. It's kind of an honor system on myself to- do I enforce this policy right here right now, or do I give a warning? Or how is this situation going to be... how's it going to benefit the student in the long run?

Jake also has to make decisions about when to step into an escalating situation. Sometimes students were able to manage the disagreement themselves, and sometimes he had to make the call about when behavior is unacceptable and needs to be remedied. He also needed to uphold policies that he doesn't necessarily support or understand:

There are little things like that that make the job kind of a pain. When it's something I know is not the biggest deal but I'm working and it's what I have to do, that's the hardest part, enforcing policy... at the end of the day, I did my job. Enforcing a policy with which he doesn't agree challenged Jake and made him recommit to his own integrity in his job.

In his role overseeing a group of students, Bradley had a student whose disruptive comments challenged his integrity. The student "said something like, 'that's so gay" and Bradley decided in that moment to wait until another class meeting to have the conversation about that term. He still questioned that decision, "that just makes me feel awful that I didn't address it right then, but it was just like, we don't have time to go into this right now, to just drop everything and address that comment, this language." Bradley had to make a judgment call about the mentor session space: he could allow the disruptive student's comments to derail the class again and have an important 
conversation about respect, or he could keep the class on track and address the comment later.

Participants discussed how they were put in the position of making value judgments about when to use their influence and position to intervene in other students' behavior, to correct it, and to take the appropriate next steps. They also reported sometimes having to make these decisions knowing that it was likely that their peers and supervisors wouldn't know that they had to make that decision. Having to make these decisions and justify them, even when it was possible no one would know either way, helped students develop their sense of integrity.

\section{Establishing Identity}

This broad category includes students' increasing comfort with a variety of their identities (Chickering and Reisser, 1993). It includes factors related to personal identity that include body and appearance, gender and sexual orientation, cultural heritage, self concept and comfort with one's roles and lifestyle, sense of self in light of feedback from significant others, self-acceptance and self esteem and personal stability and integration. Students gave several examples of how their jobs interacted with or influenced their personal identity development.

It is important to mention that although I did not collect any personal demographic information on the participants, however, through the course of their interviews about their jobs, they revealed a host of identities to me because those identities were germane to their perception of their jobs. Students talked about race, 
sexuality, gender identity, nationality and ethnicity when considering their roles. Participants' personal identities were interrelated with their perception of the work they did, and their reflections on their work was not divorced from their identities. This may indicate an opportunity for students to do work related to establishing their identity through work.

One participant provided an anecdote of how his position challenged him to develop his identity. This student mentioned crying in the shower after dealing with cultural differences related to communication within his staff team. The most difficult part of his job, he says, "was working with a group of people that had so different concept of what leadership is like and what being a student is like, and what being part of the group is like." He worked with his supervisor on his development in this area specifically.

Another participant, a self-identified transgender man, talked about how his position allowed him a comfortable, safe environment that sustained him during a difficult time. He remarked that "there are things about [my campus] that bother me, but I think that, I mean, that's always going to be the case. There's always going to be white cis-men, privileging over everyone, making stuff unfun..." He cites that through his struggles with some mental health issues, he saw a deeper value in his job. It gave him a degree of comfort and stability that helped him navigate these changes. "I like going to work. It is sort of this pocket of predictability in my life where I know I will show up and be handed tasks I can manage. I can get them done and get that rush of accomplishment." 
Although the student did not develop in this vector through his job, the consistency he felt in his job was instrumental in him weathering difficulties related to his establishing his identity.

Students also shared that they felt they had developed confidence through their jobs. Jake reported that he felt much more outgoing and confident after working in his position for a year, and Anne stated "I definitely have a lot tougher skin than I did Freshman year!" Working on campus helped these students grow in several aspects of their identities.

Finally, some participants were able to connect with others who shared similar aspects of their identity. Quinn was able to work in an environment where he and other student activists engage in social justice could work and learn together. Participants in Campus Recreation who identified themselves as recreation enthusiasts were able to connect with other students who also shared that identity, both as colleagues and students they served through their roles.

Students reported that their jobs helped them in this vector in several ways. Their roles helped them work through questions of their identity and their jobs sustained them with a supportive environment while their lives took them through that vector. Because their identities were not left at home when they went to work, they reported that their identities mattered in various ways to the work they did. Their awareness of this indicates that they had reflected on it, and demonstrates growth in this area. 


\section{Conclusion to Research Question 1}

Analysis of the data revealed themes of personal and professional development for participants. When used as a framework for organizing data that emerged related to students' personal development, Chickering and Reisser's seven vectors of student development (1993) provided an effective tool for exploring the ways in which students felt they were able to grow through their work. Many aspects of their positions helped them develop as students and as people. While some learning and development happened formally in training, much of the development happened informally, through interactions with peers, faculty and supervisors

Not every student developed in all seven of the vectors, but through the breadth of work experiences and personal characteristics this group of participants expressed, all seven of the vectors were experienced by the students in this study through their oncampus work. They developed hard skills such as certification in first aid and CPR, conflict management and even dining etiquette. They reported developing professional skills such as organization, time management, and communication. These findings are supported by other studies as well. Kuh (1995) stated that that nearly half of the students in his study reported that their employment, whether on or off campus, improved their interpersonal skills. Lewis (2008) noted that, through their work experience, students built leadership skills, and learned how to balance the multiple demands of work, school and personal life. 
Participants were able to move through the Managing Emotions vector as they navigated interpersonal relationships with peer colleagues and other students they served through their roles. Through their work, they created relationships and learned to establish healthy boundaries for themselves.

Learning to operate as an effective teammate helped them move from dependence through autonomy toward interdependence. Working on teams was developed intentionally through trainings, and was often part of the fabric of the job. RAs and people in campus recreation frequently had to rely on their coworkers to fulfill their regular job duties as well as manage critical situations.

Students reported learning from others of different backgrounds and working to become more comfortable with interacting with and understanding those different from them. Through their jobs, they had to interact with the campus population as a whole, presenting programs, building community and upholding policy with students very different from them. Through these experiences, they were developing the capacity for mature interpersonal relationships.

Participants were able to see the relationship between their work and their future goals. One student saw academic and professional congruence through her position, and several students remarked on learning, development, or experience that would benefit them in their future careers. These activities are characteristic of moving through the developing purpose vector. 
The students remarked on the value of having autonomy in their roles to carry out the mission of their department or organization the best way they could. Peer mentors felt trusted by faculty partners and empowered to construct the mentor sessions as they saw fit. Both students worked with campus recreation and RAs had to make their own decisions about when and how to enforce limits in policy. The autonomy to do their jobs (or not do those jobs) that the students discussed helped them exercise their sense of integrity.

Perhaps the area that emerged least clearly in this was an alignment with the establishing identity vector. This is curious because of the findings of Chickering et al. (1996) that through work, students are able to develop personally in this vector. Although engaging in self-reflection about differences and working to create safe spaces for others helped the participants' growth in this area, the theme was perhaps least clearly visible as aligning with the establishing identity vector. Two participants from campus recreation both self identified as recreation enthusiasts, and could explore that identity effectively through their work. Quinn, the program coordinator, worked promoting a safe, welcoming environment for a historically excluded population of students. While he identifies with this population, he did not discuss exploring that aspect of his identity through his work: he focused on the programmatic and organizational efforts required by his job. While this was the weakest of the vectors, personal identity development still appeared as a facet of students' overall development through work. 
When Chickering and Reisser (1993) argued that educational environments exerted an important influence that helps students move through the vectors of their development, he was not talking specifically about their on-campus jobs, but he did mention faculty-student interaction, curriculum, diverse student communities and student affairs programs. All of these characteristics of educational environments are part of the positions held by the students in this study and student development clearly occurs through student employment. Students in this study shared evidence that they grew and developed through all of the seven vectors in Chickering and Reisser's (1993) theory through their positions. Therefore, the answer to Research Question 1 is that students' development along all seven of Chickering and Reisser's (1993) vectors of student development can occur through on-campus student employment opportunities.

\section{Research Question 2: Academic and Social Integration}

The second question this study posed was "How does on-campus employment help and/ or hinder students' academic and social integration?" This question was answered through the data with information about integration and with insights about the relationship of mattering to the importance of students' employment experiences. These two concepts are closely related: integration is essentially students' sense that they are a part of the campus, that they have adopted the norms and values of the institution. Mattering, by contrast, is students' sense that the university community knows who they are, cares about them, depends on them, and has an emotional investment in their successes and failures. 
Both of these two categories are important to understanding students' experience with on-campus employment. This section will discuss the second research question by examining the findings in the areas of academic and social integration and then the findings on mattering in relation to the literature.

\section{Academic and Social Integration}

Academic and social integration happen as a result of becoming involved with the life of the campus, and involves students' feeling that they belong on that campus (WolfWendel et al., 2009). The themes that emerged through descriptive analysis of the data in this study revealed that academic and social integration both seem to be enhanced by students' on-campus employment. To more clearly lay out the analysis, Academic and Social Integration will be discussed separately.

Academic Integration. Students related several experiences that indicated that their academics were both challenged and supported by their employment on campus. Challenges included a steep learning curve related to managing their time, prioritizing their responsibilities, and engaging in self- care to combat stress.

The students in this study also reported learning to rise to those challenges. They received help from their peers and supervisors to do this. Quinn reported getting support from their peers, saying that sometimes, he had to let things go because school required his attention at that time: "it was me saying, 'sorry, I don't have time to get this done because I have to work on classes this week.'” Several participants also reported receiving guidance and support from their supervisors to manage these challenges. Jason 
discussed how he worked with his supervisor on stress management when things became stressful, and that his supervisor was instrumental in his managing both school and workload pressures.

Finally, several students stated that their workplaces helped support their academics because they were given spaces to study during slow times at work. Chris and Jake also mentioned having access to computers in their office area, saying that they could come in a bit before their shifts started to get some homework done. In this way, students' workplace helped them to work through some of the pressures of managing work and academics.

It is also important to mention that participants in this study reported talking about classes, teachers, grades, and longer term goals with the students with whom they worked. Jake said that he worked with other students in his major, "so we BS about that, talking about professors we've taken classes with." Academics are integrated into the workplace because students work with other students. They all share common experiences that are a part of daily informal conversations.

Social Integration. Students revealed through their interviews that the common thread within the course of all of their jobs was to talk to students on behalf of the university. This distillation of students' responsibilities in their jobs is telling: talking to students is one vital component that will be explored in this section, and communicating on behalf of the university is the other. 
An analysis of data in this study reveals that student employment, what we once thought would hinder student success by limiting interactions with peers and faculty (Tinto, 1993), has instead been perceived by the students in this study to benefit them by actually increasing their communication and interaction with peers, faculty, and staff. . For all of the participants, the amount of communication they had with others was enhanced by their jobs, because talking with students is what their job was: their job is to communicate with their fellow students.

Astin (1993) stated that even more than academic involvement and involvement with faculty, involvement with student peers has the greatest affect on students' educational experiences. Wolf-Wendel at al. (2009) suggested that because student involvement with peers is an important part of social integration, it must be part of our research on student employment. This study supports the idea of an integrated approach to studying peer interactions within student employment to help understand that dynamic and suggests that student employment may offer a method for increasing students' integration.

The other aspect of student employment that is noteworthy in the area of integration is the fact that the student employees were communicating with others on behalf of the university. Academic and social integration is defined by Tinto (1993), as degree to which students adopt the normative attitudes and values of the institution, and abide by the formal and informal rules and norms that govern the university community. Communicating with students and others, explaining the formal rules and regulations of 
the university, acting as the face of the university to incoming students is the primary role played by participants in this study. The very act of doing this job is an act of integration. Not only are these student employees better integrated into the campus because of the opportunities they get to connect with students and faculty, they are practicing their own integration when they work. Furthermore, they are working to help integrate others.

This phenomenon of "we don't go to campus events; we facilitate campus events," set within the definition of integration "the degree at which students adopt the normative attitudes and values of the institution, and abide by the formal and informal rules and norms that govern the university community" (Cabrera, Nora \& Castaneda, 1993) might further indicate that student employment is a powerful tool in integrating students socially with their institution.

\section{Mattering}

The concept of students working to integrate others into the university can be viewed another way: by putting students in roles in which they are speaking on behalf of the university, the university has set up a situation characterized by mattering. Mattering is related to students' sense (either real or perceived) that the campus has a stake in them, that others people at the institution are aware of them, that they may rely on them, that they have a stake in the students' future (Eliott et al., 2004).

Mattering is that feeling we get when others are aware of us, that they care for us, that they depend on us, and that they emote with us about our joys and failures. Students 
who report serving as role models or mentors are role modeling the informal rules and norms of the university to their fellow students.

Participants reported that their jobs gave them a sense of mattering in several ways over the course of their employment. This mattering happened on the awareness level (they were selected for the position, they got to know other students and interacted with them), the importance level (they were selected for the position over other candidates), and they are relied upon to do a job (without them, information would not be shared, students would not have a role model, etc.). When students receive evaluations, supervisors demonstrate commitment to their growth. This kind of ego-extension also occurs when supervisors provide letters of recommendation, recognize students for service, or share in students' joy over achieving academic goals such as graduation.

All of the students participating in this study reported benefits from on-campus employment in terms of mattering. They all indicated several ways that they achieved a sense that they mattered to their peer colleagues, supervisors and other students through their work. They felt they were members of communities, they were seen and known, and they felt that their contributions were important. Others cared for them and shared their joy at their successes.

Mattering has commonalities with social integration, with an important difference. Whereas integration describes a student's sense of connection to, or feelings about his or her institution, mattering is better viewed as a student's impression of how the institution feels about or connects to them. Students' experiences of employment in 
this study had characteristics of all four of Elliot et al.'s (2004) four constructs of mattering (Awareness, Importance, Reliance, and Ego Extension).

Awareness. Awareness is the most basic form of mattering, and it is framed as an understanding that a person has obtained the interest or attention of another (Eliott, 2004). When receiving attention from other people at an institution, a student might feel a greater sense of community. Schlossberg, Lynch, and Chickering (1989) posited that getting positive attention might have broader effects, leading students to generally feel better about themselves and their environment.

Several participants noted that they were approached by others in the university about applying for jobs. Anne said, "I learned about the position freshman year. My RA then came to me and a bunch of friends and said... you'd be a great candidate for this position." This scenario played out similarly for most participants: their involvement with students or staff members in the department where they would eventually work led to someone approaching them to apply for the job.

Additionally, students mentioned being known, or recognized around campus as a positive aspect of their employment. Chris valued being recognized on campus, "I definitely notice just walking around campus now-I usually walked around with my headphones on, and I can't really do that anymore because I'm constantly saying hi to people I've met through my position."Chris valued being recognized around campus and seeing people he met through work in his daily life. 
Quinn spoke of his job purpose as "to be a focal point in the group or community, and be able to help people." He spoke about having influence in the university, and using it to help others. He also mentioned that he was sought out after giving presentations, "there were definitely professors that were approaching me and saying, 'that was really nifty what you did. How can I help? Or what can I do?'” When people acknowledged Quinn's contributions, they demonstrated awareness of him, contributing to his sense of mattering.

Overall, participants in this study reported feeling like people at the university were aware of them. Through the hiring process, supervision, and the give and take of daily job tasks, students were affirmed that they mattered to others through others' awareness of them.

Importance. Importance is the feeling that other people care about us and are concerned about our well-being (Elliott et al., 2004; Rosenberg \& McCullough, 1981). Importance can be demonstrated by people indicating that they care what we want or think, or that they are concerned about our future; it is the sense that others are on our side.

Supervisors demonstrated that their students were important to them in meaningful ways. Quinn's supervisor paid particular attention to his work/ life balance: "she is also about honoring your full self and your whole self at work, and so if I just broke up with somebody, or somebody just died, or there was something pulling me away 
from work, she'd want to know" and would help him work through the hard times and manage what needed to be done.

Gail echoed this, saying her supervisor was a "kind of supportive figure when it comes to schooling and life, like if I'm having trouble in my romantic relationship, she's really open to me" Gail's supervisor demonstrated by listening that Gail mattered to her beyond the work she did, and this contributed to Gail's sense of mattering to the university.

Supervisors were frequently identified as people who helped the students feel important in their jobs, but students also felt a sense of importance through the jobs themselves. Jason had an interesting comment related to the dimension of importance, which can be perceived in both a negative and a positive way. He said that when you are a student leader, "when you make a mistake, it's not so big. In the ambassadors, it's the entire program that pays for it" when you mess up. Jason felt that if he made a big mistake, his coworkers in the program would also feel the ramifications from that error. Therefore, he felt that his work was important to others.

A feeling of being important to others at work was a common report from participants. It was realized both through supervisors and a sense of teamwork with peer colleagues. This sense students have of being important to others at work is a large part of mattering.

Reliance. Perhaps the construct of mattering most important to this study is the concept of reliance. The dimension of mattering focuses on people's sense that others 
rely on them. "When others depend on us, we feel we matter to them" (Schlossberg, LaSalle and Golec, 1989, p. 200). Reliance is the feeling that we matter because others depend on us or need us (Rosenberg \& McCullough, 1981). This dependence can be real or merely perceived; it is the perception of that dependence that is important to the construct.

This dimension emerged repeatedly in participants' interviews. Participants did not reference others depending on them; instead, they expressed very positive views of their contribution to the university and to the students they worked with. Rick stated that his students benefitted from his contributions "I don't see my role as small. I might be one of many mentors, but I think that the work we do together is really significant. We are contributing not only to the university studies program itself, but to [my institution]." Rick sees himself as part of a team that does valuable work, and this increases his sense of mattering on campus.

Gail viewed herself as part of students' educational experience: "I feel like a valuable part of the university community because I get to sit at that front desk and be an educational piece of that student's healthcare experience." Her presence goes beyond customer service to enhancing students experience through educating them.

Jake also viewed his job as important, and that others depended on him: "That's a huge thing that campus rec does is we try to make this campus healthier, we try to make individual people healthier in every aspect, not just physically but socially, and we try to make the place warm and welcoming to the people who come in" and this contribution 
influences campus. He believes in the departmental mission and he believes that his contribution to this mission makes a difference to other students.

Similar to Jake but from a housing perspective, Ethan talked about his role with his students:

I create community-I'm the spark for the fire. I give them tools and they do it themselves... I'm just also there to kind of like make sure that they are not getting too out of line, that they're healthy, that they're doing healthy habits and being the best students they can...making sure our programming and our student development... are in line with the mission of housing and the mission of the university... I'm a positive role model and that reflects down the line.

Ethan's students relied on him to help them connect to campus and to their community. Quinn said "I really like helping people...I really like making people feel safe and connected and finding themselves, who have historically not really felt a part of anything, and being like 'you belong here."' He is able to see the value that he adds to other's lives at the university, and how the work he does matters to them.

A sense that others were relying on them in their jobs was played out in students repeated consideration of the meaning they felt their work had for others, and the impact that work had on their department and the campus as a whole. This made them feel they mattered to others at their school.

Ego-Extension. The final construct within the mattering model is Ego-Extension. This construct is defined as our perception that others experience our similar emotions: 
for example, they express happiness when we succeed and lament our mistakes with us (Eliott et al., 2004). That sense that others have a stake in our success and in our failures makes us feel that we matter to them.

Jason talked about his supervisor's supportiveness of him, saying his supervisor “spends money for us to do professional development, go to conferences, do other professional development." Jason also won a national award for which his supervisor nominated him. "I never would have thought when I came to [this school] that I would win a national award before I graduated, and you know, it's just so awesome." By prioritizing spending for professional development and nominating him for that national award the supervisor demonstrated his investment in Jason's future.

When students perceive that their supervisors or coworkers have an emotional alignment with them, that others share a stake in their students' successes and failures, the students can experience ego-extension, one of the constructs of mattering. Schlossberg, Lynch, and Chickering (1989) state that in this situation, mentors or faculty members can have an impact on students they work with by demonstrating pride in their accomplishments.

\section{Conclusion of Research Question 2}

Academic and social integration is very important to students' student retention in college (Tinto, 1993). Participants in this study described numerous experiences with oncampus employment that are characteristic of social and academic integration. Core to 
their experiences was the high level of communication that these students engaged in with peers, other students, faculty and staff members.

By working in areas related to their majors and career fields, interacting with others both formally and informally, on topics related to academics and campus life, they became more academically integrated with their campus. Participants were able to study during down time at work, were often given a space in which to engage with peers informally and work on school work. They were asked about their academics by their supervisors and were assisted in the areas of time management, prioritization, and balancing their lives and workloads.

The main characteristic of all of the participants' employment roles was that they communicated with others. They interacted with students, peers, faculty, staff and supervisors, explaining policy, discussing campus life and resources, and creating relationships both formally and informally. All of these describe experiences of students who are socially integrated on campus.

Additionally, themes that emerged from this study indicated that students experienced all four constructs of mattering, including awareness, importance, reliance, and ego-extension, with the constructs of awareness and dependence being most heavily represented in participant comments. Students felt that they mattered to others because they were noticed, because they perceived their desires, thoughts and actions as being important to others, because others were invested in their successes and failures, and 
because they were engaged in work that others in the university depended upon for their success.

Mattering is one avenue into integration into the larger university community, according to Alford (1998). Further, students who feel that sense of mattering to their community realize a direct, positive relationship with their persistence toward their degree. Tovar et al.'s (2009) study was predicated on their belief that when students felt they mattered to specific people at their schools (such as other students, faculty, or advisors), they felt the effects of mattering more keenly. Tovar et al. affirm that "Positive student experiences with the learning environment, with institutional agents such as instructors and counselors, and with student-centered programs, policies, and procedures will help increase mattering" (p. 174).

Research has considered the effects of student interaction with their college environments. Thus far, the research on mattering has lagged behind the more popular (and related) theories of student involvement, integration and engagement (Astin, 1993, Tinto, 1993; Kuh, 2005). It is a rapidly expanding field of study within higher education, however, because of its importance. It has been linked directly with retention (Alford, 1998; Schlossberg, Lynch, \& Chickering 1989), and the data in this study suggest that it is a very important part of the student employment milieu. Therefore, the answer to Research Question 2 is that on-campus student employment enhances students' academic and social integration through expanding their amount of communication with students, 
faculty, and staff, and it also contributes significantly to students' sense of mattering to their campus.

\section{Research Question 3: Satisfaction}

At the end of each interview, students were asked to comment about their satisfaction with their overall experiences as college students. If needed, they were prompted to comment on how their on-campus jobs affected that satisfaction. A complex construct, satisfaction considers the experiences students have during college and the value they place on those experiences (Astin, 1993b). Analysis of the data in this study revealed that what makes students feel satisfied through their work is not the same for all students.

Students mentioned liking different aspects of their jobs. When they were asked to speak about their jobs through the lens of how those positions affected their sense of satisfaction with their overall college experience, their responses generally fell into five categories:

1. Feeling socially integrated with campus,

2. Being engaged with their campus: being involved, feeling a part, and understanding and using resources,

3. Connection between work and academic pursuits,

4. Feeling that their job mattered, and

5. Developing skills for, or understanding their jobs as a bridge to the next step in their careers. 
This section will offer an overview of these areas of student satisfaction.

\section{Social Integration with Campus}

By far, the most common topic discussed in terms of students' satisfaction with their college experiences overall was the way their student employment position enabled them to connect socially with peers and other students. Ethan, said, "I have fun with programming a lot, just getting to know other people I wouldn't get to know if I wasn't an RA.” Graham affirmed, "I’ve met a lot of very interesting people and made some good friendships." Jack went further:

Everything I have here at [my institution], even the people I've met outside campus rec, it's somehow related to campus rec, I feel like. Just being on campus all the time, being in that building, meeting people...it's been good.

Chris summarized his experience this way: "If it wasn't for campus rec, I wouldn't have spent as much time on campus and built the relationships that I have." Finally, Jason was enthusiastic about his experience on campus:

I just feel like I'm so blessed going to college, having all those people supporting me throughout the years, having a great supervisor helping me find out what I want, and having all those people support me to go and get what I want for my future.

Jason felt supported by the people he met through his job, and credits his position a great deal for his satisfaction with college.

Students reported feeling more connected to the campus community through their jobs throughout this study. The fact that they discussed themes that are related to social 
integration as important to their overall satisfaction with their college experiences is significant.

Several participants reported being more engaged on campus. When asked the question about his level of satisfaction with his college experience, Rusty shared that his job on campus made school seem even more important to him. "I wasn't as involved in the activities (before this job); I was just focused on the school work. So now I'm involved in schoolwork and the campus as well." Rick, a peer mentor, echoes this, "I don't feel lost, and with the mentoring community, I feel very connected to the campus." Jason is using his experience to mentor his younger brother, who just went to college. I tell him, “it's great you're going to college, it's great you're going to do well in class, but don't forget the other things you're going to learn in life while in college because you may never have another chance to learn that after college. So go join different organizations. Join different clubs. Get to know those people!" Jason views himself as being engaged on campus through his job, and values this engagement as part of his overall experience.

Students reported that by feeling engaged on campus, they felt more connected to the university. This sense of connection enhanced their sense of satisfaction with their overall college experience.

\section{Connections between Work and Academics}

Students also mentioned academics in their conversations about how their work related to their satisfaction with college. Rusty stated that his job made his academics feel “even more important.” Quinn felt similarly, reflecting on how being proficient in school 
and in work enables him to do a lot of self- directed challenge, and he has found a community for that. He discussed taking classes outside his major that he thinks will help him attain his future career goals. He has done organizing work before and hopes to continue in the nonprofit sector when he graduates, doing very similar work. He said:

I feel like [this institution] was where I wanted to be... [my school] is much more academically involved (than the community college in which he began his studies). People are like, 'I'm here to go to school,' and so you have very studious people that are here.

While his work allowed him to integrate socially with the campus community, his academic environment was foremost in his mind when considering what was most satisfying about his student experience.

Students' commenting on academics as part of their consideration of their overall satisfaction with college is noteworthy. It demonstrates the value they place on their time in school and underscores the importance of managing a work schedule along with academic pursuits.

Feeling that their Job was Important to Others. A sense that their jobs were important to others was also mentioned as having a positive impact on participants' overall satisfaction with being a college student. The dimensions of mattering that were represented in their comments about their satisfaction were importance, reliance and ego extension. 
Chris valued his university experience, he said, "and I've been able to give back to it, as well." Through his role with campus recreation, he was able to contribute. His job was important, so his contribution mattered. Similarly, Rick said, My job is rewarding — it's - you don't have to wonder, you know, what's the value of what you're doing-you see it very clearly. You're trying to be an advocate for education and you're trying to make a positive difference in these students' lives.

He saw the work he does as valuable because he realized that other people are affected by the work he does. He mattered to these students and they relied on him.

Gail also felt like her job mattered, that others relied on her, because she saw herself as furthering her department's mission to educate students about healthcare. She said that this makes her "feel like a valuable part of the university community because I get to sit at that front desk and be an educational piece of that student's healthcare experience." The sense of purpose she got from her job positively impacted her sense of satisfaction with her overall experience of being a student.

Finally, when Jason's supervisor nominated him for a national award, he experienced ego-extension, and he also valued "having a great supervisor-helping me find out what I want, and having all those people support me to go and get what I want for my future." Ego-extension happens when a person perceives that others share their emotions, and for Jason, this occurred when his supervisor invested in his future by demonstrating care about his future goals. 
Again, it is important to mention here that students felt a sense of mattering to be important, but this final section described only aspects of mattering that the students discussed when directly asked about their satisfaction with their overall college experience. Mattering realized through their on-campus employment improved the participants' overall satisfaction with their college experience.

Employment as a Bridge to the Next Step in their Career. When questioned about their satisfaction with their overall experience at the university, several participants mentioned opportunities they were able to take advantage of in the area of student development. Comments fell into the developmental vectors of developing competence, establishing identity, and developing purpose.

Anne's ability to develop competence through her job at school increased her overall satisfaction with college, "I feel productive, and I feel really, you know-I feel proud of myself for getting this job and for keeping it, and I feel so-I'm enjoying college and my life that much more." Ethan also grew in his competence, and linked that development to his overall satisfaction with college, saying: "My job is definitely preparing me for my next step." Ethan saw the relationship between his work and his future career, and believed the job would pay off in more ways than his paycheck. This increased his sense of satisfaction with college.

Rick said his job increased his satisfaction with his overall college experience “because I feel there's a purpose here." Jake developed in the area of his own identity. “I’ve become a more outgoing, confident individual because of my experiences here." 
His personal growth in interpersonal competence made his college life seem more satisfying.

Finally, Bradley expressed a more holistic appreciation for his own personal development through employment:

I mean even though I kind of decided in the last couple of years, as I was finishing my (academic) program - I became very sure that this was not what I want to do. I have come to accept that now, even though I've made so many mistakes along the way, and you might say that I have wasted a lot of time and money. You could say that. But, it's not a waste. In the process, and it has all, of course, if necessary to get me wherever it is I am meant to end up going.

Although Bradley's position did not allow him to connect with the content of his classes, nor did it connect directly with his professional goals, he still saw the value in the learning he was able to achieve in the experience.

It is important to underscore here that the most important part of all of these statements is not that student employees were expressing that they had developed as students, but that their development as students was specifically tied to their own satisfaction with their overall college experience. Students in this study valued the student development they were able to engage in through their on-campus positions.

\section{Conclusion to Research Question 3}

Students' ability to integrate socially through their employment was important to their overall satisfaction with college. Students valued the relationships they were able to 
make with other students, faculty and staff members through the course of their jobs. They spoke of lasting friendships and relationships made through their work that sustained them through their educational experiences.

Beyond social integration experienced through individual relationships, students expressed that their satisfaction was increased through their engagement with their campus. Their ability to know about and attend events (a characteristic of social integration), and their ability to understand and utilize campus resources enhanced their overall satisfaction with their campus experience.

Only one participant saw a direct line between her work and her academic pursuits, but several students referenced the way in which their workplace supported or enabled them to be more effective as students as a reason for their satisfaction with their college experience. They were able to study during their shifts, they were able to talk to others about school, their supervisors were understanding, and they enjoyed a great deal of flexibility in their schedules, particularly around finals. Literature about on-campus employment has not explicitly explored the value of working in an academic setting while the worker is also a student.

The theme of students' satisfaction being enhanced by the feeling that their jobs mattered reinforces the results of Cheng's (2004) study, in which he found that students' positive perceptions of their jobs were related to their perceptions of the importance of the work. He affirmed that students who felt challenged by work they viewed as important articulated that position as integral to their college experience. This feeling of 
importance, or that others relied on them enhanced their sense of mattering, which affected their sense of satisfaction.

Finally, several students who spoke about their overall satisfaction with their college experience referenced appreciation for the ways in which their job was preparing for their next step in their careers. For three participants, it was networking and practicing in their chosen field. For several others, it was building skills in areas that included working with a variety of people, managing demanding schedules through time management, and becoming more confident overall.

The importance of student satisfaction to their retention is unambiguous. It has been found to be positively related to student motivation, retention, and persistence (Beil \& Shope, 1990; Knox, Lindsay, \& Kolb, 1992; Lenning, 1982; Pascarella, 1982; Elliott and Shin, 2002; \& Astin, 1993; Tinto, 1993). Tinto (1993) asserted that satisfaction is a proxy for retention. Student satisfaction is important, and the fact that students identify diverse aspects of their on-campus employment as contributing to the construct answers Research Question 3.

\section{Student Employment Reconsidered}

Beyond the research questions this study was designed to address, this study data offer insight into students' employment experiences based on job type and supervision. These areas don't fit neatly into any one of the research question sections. Instead, they cut across all of them. They are included here because both are important to the implications of research and practice regarding on-campus student employment. 


\section{Job Type}

It has been suggested through the literature that job type is important. Chickering et al. (1996) suggest that, through their work experiences, students move from their first jobs which may not be related to their career goals, through different positions of employment toward positions more closely related to future plans. Thus, student employment can be a part of career development. Autonomy has been viewed as a benefit for student employees. Derous and Ryan (2008) found that the amount of autonomy to determine job tasks and autonomous motivation students felt in their positions had a positive influence on outcomes, including GPA, sense of well being and attitude about studying.

Other scholars have also postulated that different types of student work would yield different results, but it has not yet considered those differences (Riggert et al., 2006; Salsbury et al., 2009). Research into student employment has not accounted for the specific dynamics of the workplace, including the level of meaning students attribute to the position (Cheng, 2004) or how relevant the work is to their long-term goals (Derous \& Ryan, 2008).

This study was designed to allow examination of how different position types affected student employees. By carefully constructing job categories based on level of autonomy, responsibility and supervision, it was possible to examine students' experiences with on-campus employment through that perspective. The data indicate that job type is important to students' experiences, and that it is important that the job fits the 
student's needs, interests, and abilities. Therefore, this study reinforces Cheng's (2004) findings that students felt their job was more of an integral part of their on-campus experience when they found meaning in their work, and felt it was important. Students were less uniform in valuing the level of challenge they felt the job offered them, however. While that feeling of rising to a challenge of important work resonated with some of the participants, others did not report their work being particularly challenging. Yet, they still valued it for other benefits it brought them, such as a sense of community, the opportunity to work and network within their chosen field, and the opportunity to enjoy support and growth through their relationship with their supervisor.

While this study suggests that students do yield different outcomes from different types of jobs, the assumption should not be that some types of jobs are better than others. Participants reported developing a host of skills through their work, including time management, organization, prioritization, efficiency and communication skills regardless of their job category. Students' skill development in these areas is supported by the literature as well (Lingrosso, 2007; Dundes \& Marx, 2006; Kuh, 1995). As the positions varied and as the students themselves varied, the outcomes did as well. It seems more important to find a position that fit well with the needs and growth areas of the student worker than find a job with high autonomy and responsibility. 


\section{Supervision}

Throughout students' narratives, the contributions of supervisors were very important. They contributed significantly to students' integration into the university, sense of mattering, and personal development.

Supervisors were instrumental in helping students integrate socially into the university by orienting them into their positions through trainings, workshops, and regular supervision, as well as just by hiring them into the position. Supervisors enhanced academic integration by offering flexible schedules around finals and midterms, talking to students about academics and career goals, and helping students manage their time and stay organized. During down times, they encouraged students to study for classes on the job, as well.

Supervisors emerged overwhelmingly as entities that helped students feel they mattered. They demonstrated awareness by noticing students, hiring them and working with them. They demonstrated that students were important to them by meeting with them, helping them work through problems, and recognizing them for a job well done. They demonstrated reliance by entrusting student employees with the care of other students, and ego-extension by ensuring that students were well trained to be successful in their jobs, recognizing excellent performance, and helping them reach their life goals through extra development, coaching, and letters of reference.

Student development was also greatly enhanced by supervisors. Professional development training and regular supervision helped students translate their experiences 
on the job into hard professional skills like communication, conflict management. and crisis management. By helping students reflect on mistakes, explore and troubleshoot conflicts, and reflect on lessons learned on the job in a safe space, supervisors helped students develop holistically in the areas described by Chickering and Reisser's (1993) Seven Vectors of Student Development. If every student benefitted from a trained staff member who worked to support them, oriented them to campus services, offered guidance and feedback, and acknowledged a job well done, retention would look very different.

\section{Conclusion to Student Employment Reconsidered}

The study was designed to answer questions related to students' development, integration and satisfaction. Through discussing their jobs, however, the students also talked about how they interacted with the specific type of job they had and how it fit with their goals and skill sets. They also spoke at length about the importance supervisors had on their experiences and how those relationships enhanced their learning, integration and satisfaction with school. 


\section{CHAPTER 6: Implications}

Research on the effects of on-campus employment on student outcomes has suggested that employment may yield gains in various measures of students' success (Cheng, 2004, Derous \& Ryan, 2008, Pike et al., 2008). The purpose of this study was to explore how on-campus employment affects students' college experience. Findings from this study articulated characteristics of on-campus employment important to students' development, academic and social integration, and overall satisfaction with college life.

The data from this study indicate that when student employment works well, students are able to develop through the vectors described by Chickering \& Reisser (1993). Working on teams, autonomous decision making and communicating with diverse groups of students, faculty and staff provide an educationally rich environment for students to explore development.

The data also indicate that through employment, students are able to integrate into campus life both academically and socially. By working with peers, having a place to study, being encouraged to do schoolwork during downtime, and discussing academics, time management, prioritization and balance with supervisors and peers, they connect more closely with the academic life of the institution.

Students are able to integrate socially through their positions, as well; all participants reported that communicating with other members of the university community was the primary function of their employment. They explained policies and 
procedures, built community for students, and created relationships with peer colleagues both formally through training and teambuilding, and informally by hanging out.

Students in this study also revealed that their sense of mattering to other people and to their wider campus was enhanced by their work on campus. People know who they are because of their jobs, students develop caring relationships with their peers and supervisors, students perceive that they are relied on by others through their jobs, and students sense that others are invested in their futures. Ultimately, being put into positions to speak on behalf of the university served to deepen their sense of integration into the fabric of the campus.

Students' on-campus employment positively impacted their satisfaction in several ways. They were socially integrated with campus, they felt engaged in the life of the campus, they saw relationships between their work and their academic or career pursuits, and they viewed their jobs as an effective stepping stone to their future goals through learning skills and developing important traits. Finally, their perception that the work they did was important to others lent to their overall sense of satisfaction on campus.

Two final areas of contribution from this study are job type and supervision. Data revealed that the important aspect was that fit; that is, having an appropriate fit to the specific career goals and developmental needs of the student was more important than levels of autonomy and responsibility to students' development, integration, and satisfaction. Supervision was revealed to be very important to students' success. Supervisors assisted students through developmental vectors, aided in their academic and 
social integration by helping them connect to peers, manage conflicts and balance work, school and life. More than any other group identified by participants, supervisors positively influenced students' sense of mattering. Student employees value those relationships, and are able to articulate impacts their supervisors have on them.

Based upon the findings from the data in this study, this chapter concludes the paper by offering implications for both research and student affairs practice.

\section{Implications}

The data analysis from this study helped articulate how students engaging in oncampus employment opportunities spent time on their jobs and how those jobs impacted their ability to grow, become integrated with campus, and enjoy their college experiences. This section explores some potential implications for future research and practice.

\section{Implications for Research}

This study contributes to our understanding about on-campus student employment. Analysis of the data indicates that through their positions, participants realized gains in student development, integration, sense of mattering and overall satisfaction with their college experience. Findings underscore the importance of the supervisory relationship to all of these constructs. Findings also indicate that students' fit within their positions in terms their own needs and career goals matters. In fact, this concept of fit is more important to students' development, integration, sense of mattering 
and overall satisfaction than simply obtaining a position of high autonomy and responsibility.

There is a need for further research, and the focus of the research needs to shift to a more cohesive approach that stresses well defined variables and definitions (Riggert et al., 2006). This study adds to the existing body of research, explaining how work experiences can influence a student's integration, sense of mattering, development, and satisfaction. Analysis of the data raises a number of important questions that are yet to be answered through research. This section explores those questions and makes suggestions for future research.

While the data in this study helped describe students' experiences with on-campus employment and how it facilitated their development, it falls short of formulating a model for how that may happen. Development of a model explaining student employment's impact on development would be very useful and should be pursued.

While this study suggests that working on campus can yield positive effects for students related to academic integration, research should be done to quantify how different types of jobs affect classroom learning. We understand from the literature that there is a curvilinear relationship between the hours students work on campus and measures of their success. This study indicates that students benefit from on-campus employment, but it is not yet clear how, or how those benefits impact that relationship.

This study also reveals that students work and interact closely with student affairs professionals as supervisors, referral agents, and sometimes as colleagues through their 
jobs. However, literature on involvement and integration has not delved into the value of communication or relationships with university administrators. Student affairs administrators have the opportunity to work more closely with students in many cases than faculty members, so a study that explored what kind of value student relationships with administrators may have to their overall success could be telling.

Supervision emerged as a key component of students' experiences in their positions, and those experiences reached beyond the job into their overall satisfaction with college. Supervision of students would be a valuable area of study to determine what makes supervision effective not just from a staff development standpoint but from a student development perspective as well.

Because this study focused on a population of students that was successful (all were returning in their roles, and all were recommended for interview by their supervisors), its value is that it offers a snapshot of what student employment looks like when it's working well for the student workers. A complementary study might examine on-campus employment that did not work well for the students involved. If students reported negative influences from working on their social or academic integration, their development, or their satisfaction, what might be the signs they gave before they were overwhelmed?

Finally, this was a small study done on one campus that focused on the experiences of students who were successful in their roles both as students and as student workers. Much more work needs to be done to define and quantify aspects of students' 
employment experiences to help realize the value each part has to the whole. This will help us design more effective employment opportunities.

\section{Implications for Practice of Student Affairs Professionals}

Student employment has the potential to yield benefits to students far beyond the paycheck. Student Affairs Practitioners understand the challenge of building effective environments for student development and learning that students will take advantage of. Even when we know we can show empirically that a given experience will be worthwhile for students, it can be difficult to get students to engage in those opportunities, particularly when they have huge demands on their time. One of those demands on students' time is usually work, because students respond to decreasing financial support and rising college costs by working.

With on-campus employment, we have a carrot to engage students in learning environments. Thus, we engage people who wouldn't necessarily reach out for our services. They may not be informed about our services, and they certainly may not know they need these services. Student employment in this study is characterized by training students about university resources. These employees have a dedicated university professional charged with helping them succeed at their jobs and in their studies. These supervisors have the knowledge about resources, understanding and trust of the students, and a unique opportunity to connect students to each other, to the university, and to resources they may need. Student workers may actually become sources on how to find 
out about on these services, in many cases, because it's their job to tell other students about them.

This study was predicated on the assumption that student employment could be re-imagined as a learning opportunity for students. This idea is not new. Perozzi, Rainey, \& Wahlquist (2003) remind us that we are compelled to reflect on the opportunities for growth offered through employment opportunities. By developing more integrated experiences offered through employment, we can continue to improve the overall development of our students. Similarly, Lewis (2010) recommends that supervisors of on-campus student employees utilize learning outcomes established by leaders in the field of student development to enhance the educational capacity of the workplace, to develop a "comprehensive, learning-centered student employment program."

Imagining student employment opportunities as learning opportunities opens a host of possibilities for student learning. Lundberg (2004) suggests, "Higher education has long used internships, clinical experiences and off- campus practica as learning vehicles, but the workplace and its learning potential has been relatively over looked" (p.210). Some institutions have begun to operationalize the idea of the paid, undergraduate internship on their campuses, utilizing a curriculum and learning outcomes for your students that they would realize through both training programs and through the regular course of their jobs.

The practical implications recommended here are drawn from students' comments about how their employment on-campus positively affected their overall satisfaction with 
their college experience. Satisfaction has been called a proxy for retention (Tinto, 1993); therefore, the fact that students mentioned these areas of their employment in the context of their sense of satisfaction with school is important. The areas students cited as contributing to their sense of satisfaction include feeling socially integrated with other people on campus, being engaged with their campus (being involved, feeling a part, and understanding and using resources), feeling that their jobs mattered, identifying a connection between their jobs and their academic pursuits, and developing skills for, or understanding their jobs as a stepping stone to their career goals.

Student employment can help students feel socially integrated on campus through offering employment that requires them to speak on behalf of the department to other students, faculty and staff members. Working on teams with peer colleagues not only contributes to students' sense of satisfaction, but to their development as well. Team work should be encouraged and enhanced through purposive team building and work environments that include a space for informal interactions before and after work, and during downtimes on shift.

To help student feel engaged with and part of their campus, they should be trained as referral agents for other students on campus resources, and encouraged to use those resources themselves. They should also be made aware of the larger context of the roles they play within their department and how their department's work, and their own, relates to the larger goals of the university. To the degree possible, students should be helped to understand the meaning in their work, have opportunities to reflect on their work, and 
look for ways to develop in their jobs and explore positions of increasing difficulty, responsibility, and autonomy. Understanding the context of their work, having control of decision making about it and seeing how it matters to the larger campus community enhances students' satisfaction with their overall educational experience.

To help students identify a connection between their jobs and their academics, there are several things that can be done. First, because a particular student's fit with their position emerged as important to their development, integration and satisfaction than job type, students would be best paired with jobs that match their skill set, growth potential, and career trajectory. Students reported that they were satisfied in their jobs regardless of the job type, and they indicated that what mattered most to them was that they were able to achieve their own goals through their positions. Additionally, spaces for students to study, and encouragement to study during "down time" at work help students manage the balance of work and school responsibilities. Finally, offering a flexible schedule particularly around finals week and having regular check-in conversations about academics can help seat employment as a valuable part of the students' overall college experience.

To help students realize their jobs as a next step in their career paths, supervisors should be sure to give critical feedback through evaluations. Evaluations of student employees should reflect the value of learning in the workplace, serving as formative and summative tools, and covering both job performance and learning. Again, job fit is important in this area: students should be selected for fit with their long-term career 
trajectory to the degree possible, and opportunities to grow and develop in ways that will benefit that trajectory should be explored. An RA who wanted to enter medical school might specialize in programming around health issues, for example.

Supervision is important to students' satisfaction. Students in this study commented that their satisfaction was increased by their ability to develop through their jobs, but also that they felt they mattered to their supervisors and their peer colleagues. They view support from their supervisors as coming through listening and intentional time spent together. Students respond well to supervisors when they see them in a friend or mentor role: as supportive leaders who challenge them, encourage them, and have an investment in their future.

Overall, it is clear that communicating with peers, faculty, administrators and others is beneficial to students' integration and development. This happens through students' on-campus employment, and student employees learn more about campus resources and activities through their roles, as well. Since these kinds of interactions and experiences have positive influence on students' overall satisfaction with their college experience, on-campus student employment has value. Therefore, practitioners should create more options for students to work for their institutions.

While the consequences of failing to explore better learning through on-campus student employment are minimal, the potential benefits at little cost make the conversation compelling. In this climate of decreased resources and increased 
accountability, higher education professionals cannot afford to waste any opportunity to maximize student learning.

\section{Concluding Notes}

In 1996, The American College Personnel Association released its seminal document, The Student Learning Imperative. Situated in a context of diminishing resources, increased demand for higher education, and increased calls for accountability, the document is a call for increased creativity, dedication, and intentionality related to student learning in higher education.

Over the last seventeen years since this document was drafted, little has changed. Student affairs professionals remain aware of state of our field and the creative work that must be done to develop effective educational programs and services for a rapidly evolving student population in an increasingly diverse and global community. Examples of calls to action in this area include the National Association of Student Personnel Administrators (NASPA)/ American College Personnel Association (ACPA) Joint Taskforce on Student Learning report, Powerful Partnerships (1998), and the 2005 Association of American Colleges \& Universities' Liberal Education and America's

Promise (LEAP) initiative. Even the outline of professional competency areas for Student Affairs that was adopted by the boards of directors of both ACPA and NASPA in 2010 offers a call to develop new ways of understanding student development and crafting educationally purposeful environments for our students. Our students and their needs 
have changed; the call for excellence, creativity, and accountability in our practice has not.

During the last decade, "there has been substantial growth in interest regarding student persistence in higher education. This interest has been driven... by practical considerations of student recruitment and maintaining enrollments" (Bers and Smith, 1991). In addition, government funding for higher education has dropped significantly since the Student Learning Imperative was published, and student tuition has skyrocketed. Students are increasingly combining work and school to achieve their academic goals. More students are working and they are working more hours. By revisiting student employment as a learning environment that fosters deeper connection to and satisfaction with the university, student affairs professionals can take advantage of existing structures to help increase student satisfaction and retention.

Scholarship has begun to move beyond Astin's and Tinto's (1993, 1993) opinions that student employment is a negative influence on student success (Pike et al., 2008; Perna 2010; Perozzi et al. 2003; Lundberg 2006). Instead of viewing employment as a hindrance to students' development, scholars argue, student affairs divisions should continue to lead the way in employing students, and should model the way for other units at the institution. Approaching on-campus student employment opportunities as potential developmental opportunities has been called for by researchers and is supported by this study. 
Practitioners also stand to benefit from a student development perspective of student employment. In a climate of shrinking budgets and increased accountability, practitioners are looking for methods to enhance students' experiences on campus in ways that are not costly from either a financial or a human resources standpoint. This is particularly true when working to facilitate the success of students with the most need. Understanding more about ways on-campus employment helps students develop, integrate with campus, feel a sense of mattering to the campus, and enhance their overall satisfaction with their educational experiences, will enable practitioners to create more effective employment opportunities and relationships within existing structures. 


\section{References}

ACPA and NASPA Joint Task Force on Professional Competencies and Standards (2005) ACPA and NASPA professional competency areas for student affairs practitioners. Retrieved February 2, 2012 from: http://www.naspa.org/regions/regioniii/Professional\%20Competency.pdf

Alford, S. M. (1998). The impact of inner-city values on student social adjustment in commuter colleges. NASPA Journal, 35(3), 225-233.

American College Personnel Association. (1996). The student learning imperative: Implications for student affairs. Washington, DC: Author.

Association of American Colleges and Universities, Washington, DC. (2007). College learning for the new global century: A report from the national leadership council for liberal education \& America's promise. Association of American Colleges and Universities.

Astin, A. (1984). Student involvement: A developmental theory for higher education. Journal of College Student Personnel, 25, 297-308.

Astin, A. (1993) Preventing students from dropping out. San Francisco: Jossey- Bass.

Astin, A. W. (1993b). What matters in college? Four critical years revisited. San Francisco, CA: Jossey-Bass.

Beekhoven, S., DeJong, U., \& Van Hout, H. (2002) Explaining academic progress via combining concepts of integration theory and rational choice theory. Research in Higher Education, 43(5), 577-600. 
Beil, C., \& Shope, J. H. (1990). No exit: Predicting student persistence. Paper presented at the annual AIR 1990 Forum, Louisville, KY.

Beltyukova, S. A., \& Fox, C. M. (2002). Student satisfaction as a measure of student development: Towards a universal metric. Journal of College Student Development, 43(2), 161-169.

Bers, T. H., \& Smith, K. E. (1991) Persistence of community college students: The influence of student intent and academic and social integration. Research in Higher Education, 32(5), 539-556.

Black, A. E., \& Deci, E. (2000). The effects of instructors' support and students' autonomous motivation on learning organic chemistry: A self-determination theory perspective. Science Education, 84(6), 740-756.

Bozick, R. (2007). Making it through the first year of college: The role of students' economic resources, employment, and living arrangements. Sociology of Education, 80(3), 261-284.

Broughton, E. A., \& Otto, S. K. (1999). On-campus student employment: Intentional learning outcomes. Journal of College Student Development, 40, 87-89.

Cabrera, A. F., Nora, A., \& Castañeda, M. B. (March 01, 1993). College persistence: Structural equations modeling test of an integrated model of student retention. The Journal of Higher Education, 64(2), 123-139.

Cermak, K., \& Filkins, J. (2007). On-campus employment as a factor of student retention and graduation. The Journal of Student Employment, 11(1), 10-14. 
Cheng, D.X. (2004). To work or not to work: The impact of work on students' college experience. Paper presented at the Association for Institutional Research Annual Forum.

Cheng, D.X., \& Alcantara, L. (2007). Assessing working students' college experiences: a grounded theory approach. Assessment \& Evaluation in Higher Education. 32(3), 301- 311.

Chickering, A. W., Frank, I. \& Robinson, V. (1996). Encouraging student development through student employment [Monograph]. In R. Kincaid (Ed.), Student employment: Linking college and the workplace (11-24). Columbia, SC: National Resource Center for the Freshman Year Experience \& Students in Transition.

Chickering, A. W., \& Reisser, L. (1993). Education and identity. San Francisco: JosseyBass Publishers.

College Board (2010). Paying for college: Students from middle-income backgrounds. Trends in Higher Education Series. New York: College Board Publications. Council for the Advancement of Standards in Higher Education (2003). The book of professional standards for higher education 2003. Washington, DC: Author.

Creswell, J. W., \& Creswell, J. W. (2007). Qualitative inquiry \& research design: Choosing among five approaches. Thousand Oaks: Sage Publications.

Dalton, J., \& Crosby, P. (2008). Challenging college students to learn in campus cultures of comfort, convenience and complacency. Journal of College \& Character 9, 15. 
Derous, E., \& Ryan, A. M. (2008). When earning is beneficial for learning: The relation of employment and leisure activities to academic outcomes. Journal of Vocational Behavior, 73(1), 118-131.

Donald, J. G., \& Denison, D. B. (1996). Evaluating undergraduate education: The use of broad indicators. Assessment \& Evaluation in Higher Education, 21(1), 23-40.

Dundes, L., \& Marx, J. (2006). Balancing work and academics in college: Why do students working 10 to 19 hours per week excel? Journal of College Student Retention, 8(1),107-120.

Educational Resources Information Center (2000). The national study of the operation of the federal work-study program: Summary findings from the student and institutional surveys. Washington, D.C: The Service. Retrieved from: http://www2.ed.gov/offices/OUS/PES/finaid/FWS_summary_dec_2000.pdf

Elliott, K. M., \& Shin, D. (2002). Student satisfaction: An alternative approach to assessing this important concept. Journal of Higher Education Policy and Management, 24(2), 197-209.

Elliott, G. C., Kao, S., \& Grant, A. (2004). Mattering: Empirical validation of a socialpsychological concept. Self and Identity, 3, 339-354.

Engelkemeyer, S. W., \& Brown, S. C. (1998). Powerful partnerships: A shared responsibility for learning. AAHE Bulletin, 51(2) 10-12.

Furr, S. R., \& Elling, T. W. (2000). The influence of work on college student development. NASPA Journal, 37, 454-470. 
Heiselt, A. K., \& Bergerson, A. A. (2007). Will work for a college education: An analysis of the role employment plays in the experiences of first-year college students. Higher Education in Review, 4, 83-106.

Horn, L., Malizio, A. G., United States, \& National Center for Education Statistics (NCES) (1998). Undergraduates who work. Washington, D.C.: U.S. Dept. of Education, Office of Educational Research and Improvement.

Kantrowitz, M. (2011) The distribution of grants and scholarships by race. Retrieved from http://www.finaid.org/scholarships/20110902racescholarships.pdf

Kasworm (2010). Adult workers as undergraduate students: Significant challenges for higher education policy and practice. In L. Perna (Ed.), Understanding the working college student (pp. 23-42). Sterling, VA: Stylus.

King, T. \& Bannon, E. (2002). At what cost? The price that working students pay for a college education. Washington, DC: State PIRGs’ Higher Education Project

Knox, W. E., Lindsay, P., \& Kolb, M. N. (1992). Higher education, college characteristics, and student experiences. The Journal of Higher Education, 63(3), $303-324$.

Kuh, G. (1995) Out-of-class experiences associated with student learning and personal development. The Journal of Higher Education, 66,123-155.

Kulm, T. L., \& Cramer, S. (2006). The relationship of student employment to student role, family relationships, social interactions and persistence. College Student Journal, 40(4) 927-938. 
Lenning, O. T. (1982). Variable-selection and measurement concerns. In E. T. Pascarella (Ed.), Studying student attrition (pp. 35-53). San Francisco, CA: Jossey-Bass.

Lewis, J. S. (2010). Job fare: Workplace experiences that help students learn. In L. Perna (Ed.), Understanding the working college student (pp. 155-176). Sterling, VA: Stylus.

Light, R. J. (2001) Making the most of college: Students speak their minds. Cambridge, MA, Harvard University Press.

Lingrosso, C. S. (2007). Student engagement and career development through the first year student employment experience. Journal of Student Employment, 11(1), 4-9.

Lundberg, C. (2004). Working and learning: The role of involvement for employed students. NASPA Journal, 41, 201-215.

Marshall, C., \& Rossman, G. B. (1989). Designing qualitative research. Newbury Park, CA: Sage Publications.

Maslow, A. H. (1970). Motivation and personality. New York: Harper \& Row. McCormick, A.C., Moore III, J.V., \& Kuh, G.D. (2010). Working during college: Its relationship to student engagement and education outcomes. In L. Perna (Ed.), Understanding the working college student (pp. 179-212). Sterling, VA: Stylus.

Merriam, S.B. (2009) Qualitative research: A guide to design and implementation. San Francisco: Jossey- Bass.

Milem, J. (1998) Attitude change in college students. Journal of Higher Education, 69, 118-130. 
National Center for Education Statistics. (2003). Work first, study second: Adult undergraduates who combine employment and postsecondary enrollment (NCES 2003-167). Washington, DC: Author. Retrieved from http://eric.ed.gov/PDFS/ED482529.pdf

Pascarella, E. T. (Ed.). (1982). Studying student attrition. San Francisco, CA: Jossey- Bass.

Pascarella, E. T., Edison, M. I., Nora, A., Hagedorn, L. S., \& Terenzini, P. T. (1998). Does work inhibit cognitive development during college?

Educational Evaluation and Policy Analysis, 20(2), 75-93.

Pascarella, E. T., \& Terenzini, P. T. (2005). How college affects students: Vol. 2. San Francisco: Jossey-Bass.

Perna, L.W. (2006) Improving educational opportunities for students who work. Retrieved from http://www.indiana.edu/ ipas1/documents/Perna\%20Improving\%20Educational \%20Opportunities.pdf

Perna, L.W. (2010 a) Understanding the working college student. Academe, 96(4), 30-33. Perna, L.W. (2010 b) Conclusions and recommendations for policy, practice and future research. In L. Perna (Ed.), Understanding the working college student (pp. 283308). Sterling, VA: Stylus.

Perozzi, B., Rainey, A., \& Wahlquist, Z. (2003) A review of the effects of student employment on academic achievement. ACUI Bulletin, 71,10-14. 
Pike, G., \& Kuh, G. (2005) First- and second-generation college students: A comparison of their engagement and intellectual development. The Journal of Higher Education 76 (3), 276-300.

Pike, G., Kuh, G., \& Massa- McKinley, R. (2008). First year students' employment, engagement, and academic achievement: Untangling the relationship between work and grades. NASPA Journal, 45, 560- 582.

Prospero, M., \& Vohra-Gupta, S. (2007). First generation college students: Motivation, integration, and academic achievement. Community College Journal of Research and Practice, 31(12), 963-975.

Pusser, B. (2010). Of a mind to labor: Reconceptualizing student work and higher education. In L. Perna (Ed.), Understanding the working college student (pp. 134154). Sterling, VA: Stylus.

Riggert, S. C., Boyle, M., Petrosko, J.M, Ash, D., \& Rude- Parkins, C. (2006). Student employment and higher education: Empiricism and contradiction. Review of Educational Research, 76(I), 63-92.

Rosenberg, M., \& McCullough, B. C. (1981). Mattering: Inferred significance and mental health among adolescents. Research in Community Mental Health, 2, 163-182.

Sabo, S. (2010) Down but not out. Business Officer Magazine. Retrieved from http://www.nacubo.org/Business_Officer_Magazine/Magazine_Archives/JulyAug ust_2010/Down_But_Not_Out.html 
Salsbury, M.H., Padgett, R. D., \& Pascarella, E. T. (2009) The effects of work on the educational experiences and liberal arts outcomes of first year college students. Retrieved from http://www.liberalarts.wabash.edu/storage/EffectsofWorkDraft_SalisburyPadgett Pascarella_AIRProposal2009.doc

Sarasohn, D., (2010). Failing grade: Oregon's higher education system goes begging. Portland, OR: New Oregon Publishers.

Schuh, J. H., \& Upcraft, M. L. (2000). Measuring student satisfaction and needs. In M. J. Barr, M. K. Desler, \& Associates (Eds.), The handbook of student affairs administration (2nd ed., pp. 265-285). San Francisco, CA: Jossey-Bass.

Schlossberg, N. K., Lynch, A. Q., \& Chickering, A. W. (1989). Improving higher education environments for adults: Responsive programs and services from entry to departure. San Francisco: Jossey-Bass Publishers.

Schlossberg, N. K., Lassalle, A., \& Golec, R.(1989). The mattering scales for adult students in higher education. College Park: University of Maryland.

Schweinle, A., \& Helming, L. M. (2011). Success and motivation among college students. Social Psychology of Education, 14(4), 529-546.

Staklis, S., Chen, X., \& National Center for Education Statistics (NCES) (2010). Profile of Undergraduate Students: Trends from Selected Years, 1995-96 to 2007-08. Web Tables. NCES 2010- 220. Retrieved from http://nces.ed.gov/pubs2010/2010220.pdf 
Strage, A. A. (1999). Social and academic integration and college success: Similarities and differences as a function of ethnicity and family educational background. College Student Journal, 33(2), 198.

Tinto, V. (1975). Dropout from higher education: A theoretical synthesis of recent research. Review of Educational Research, 45, 89-125.

Tinto, V. (1993). Leaving college: Rethinking the causes and cures of student attrition. Chicago: University of Chicago Press.

Tovar, E., Simon, M., \& Lee, H. (2009). Development and validation of the college mattering inventory with diverse urban college students. Measurement and Evaluation in Counseling and Development, 42(3), 154-178.

Turner, D. W. (2010) Qualitative interview design: A practical guide for novice investigators. The Qualitative Report, 15(3) 754-760.

Tuttle, T., McKinney, J., \& Rago, M. (2005). College students working: The choice nexus (IPAS Topic Brief). Bloomington, IN: Project on Academic Success.

Wenz, M., \& Yu, W.-C. (2010). Term-time employment and the academic performance of undergraduates. Journal of Education Finance, 35(4), 358-373.

Wolf-Wendel, L., Ward, K. K. A., \& Kinzie, J. J. L. (2009). A tangled web of terms: The overlap and unique contribution of involvement, engagement, and integration to understanding college student success. Journal of College Student Development, $50(4), 407-428$. 
Appendices 


\section{Appendix A: IRB Approval}

\section{Research and Strategic Partnerships \\ Post Office Box 751 (RSP) 503-725-3423 tel Portland, Oregon 97207-0751 503-725-8170 fax rsp@pdx.edu \\ 龟 Portland State \\ Portland State University HSRRC Memorandum}

To: Shannon Timm Watson

From: Todd Bodner, Chair, HSRRC 2012

Date: June 25, 2012

Re: Your HSRRC application titled, "Student Employment as Student Development" (HSRRC Proposal \#122225)

In accordance with your request, the Human Subjects Research Review Committee has reviewed your proposal referenced above for compliance with DHHS policies and regulations covering the protection of human subjects. The committee is satisfied that your provisions for protecting the rights and welfare of all subjects participating in the research are adequate, and your project is approved.

Please note the following requirements:

Changes to Protocol: Any changes in the proposed study, whether to procedures, survey instruments, consent forms or cover letters, must be outlined and submitted to the Chair of the HSRRC immediately. The proposed changes cannot be implemented before they have been reviewed and approved by the Committee.

Continuing Review: This approval will expire 6/22/2013. A Continuing Review Report (available in RSP) of the status of the project is submitted to the HSRRC approximately two months before the expiration date, and that approval of the study is kept current.

Adverse Reactions: If any adverse reactions occur as a result of this study, you are required to notify the Chair of the HSRRC immediately. If the problem is serious, approval may be withdrawn pending an investigation by the Committee.

Completion of Study: Please notify the Chair of the Human Subjects Research Review Committee (campus mail code ORSP) as soon as your research has been completed. Study records, including protocols and signed consent forms for each participant, must be kept by the investigator in a secure location for three years following completion of the study. 
If you have questions or concerns, please contact the HSRRC in the Office of Research and Strategic Partnerships, Market Center Building, Suite 620, 1600 SW Fourth Ave, Portland OR 97207 (503)725-2243.

cc: Roxanne Treece

Christine Cress 


\section{Appendix B: Invitation Email Text}

\section{Dear [prospective subject's name]:}

My name is Shannon Timm Watson, and I am a doctoral student at Portland State University. I am beginning a study on the ways on- campus employment affects college students' experiences and would like to invite you to participate.

You are being asked to take part because of your job on campus, specifically your work as a (their title). As part of the study, I am interested in your opinions and attitudes about your job and its affect on your experience as a student, and hope that the information I collect will help us to better understand how different parts of students' jobs affect their college experiences differently. If you decide to participate, you will be asked to If you decide to participate, you will be asked to engage in a one- hour long interview that will take place in a quiet study room in the library and which will be digitally audio recorded. Questions will be related to your job on campus and to your general college experience, and your sense of satisfaction. Additionally, you will be emailed with follow up questions up to a month after the interview with additional questions that will arise from analyzing data collected from interviews with a total of ten participants.

While participating in this study, the risks to you will be minimal, and may include anxiety and worry about revealing negative feelings or opinions about coworkers and supervisors. Participants may also feel a sense of anxiousness when they examine the way that working can get in the way of their academics. I will help maintain your confidentiality by assigning all participants pseudonyms before transcribing the interview, and will use those pseudonyms when publishing data.

You may also benefit from this study by reflecting on the ways your work enhances your college experience. You may feel a sense of synergy between work and school, and you may come to value your work in new ways. You will also receive a $\$ 5.00$ Starbucks gift card for your participation.

Your participation is voluntary. You do not have to take part in this study, and it will not affect your position or your relationship with your supervisor. You may also withdraw from this study at any time without affecting your position or your relationship with your supervisor.

Please keep a copy of this letter for your records.

If you have questions or concerns about your participation in this study, contact Shannon Timm at shannonw@pdx.edu or 503.725.5652. If you have concerns about your rights as a research subject, please contact Research and Strategic Partnerships, Market Center Building $6^{\text {th }}$ floor, Portland State University, (503) 725-4288.

Sincerely,

Shannon Timm Watson

Student Activities and Leadership Programs 


\section{Appendix C: Informed Consent}

You are invited to participate in a research study conducted by Shannon Timm Watson, a doctoral student in the Educational Leadership \& Policy program of the Graduate School of Education at Portland State University. The researcher hopes to learn how your employment on campus affects your life as a student, including how you spend your time, where you put your energy, and how your work impacts your college experience. The research will be published in a dissertation to help the researcher meet requirements for a doctoral degree, and the researcher will be working with Professor Christine Cress as her advisor. You were selected as a possible participant in this study because of your on- campus employment position, specifically, your work in (which specific job I'll be interviewing about, because students sometimes work multiple jobs on campus).

If you decide to participate, you will be asked to engage in a one- hour long interview that will take place in a quiet study room in the library and which will be digitally audio recorded. Additionally, you will be emailed with follow up questions up to a month after the interview with additional questions that will arise from analyzing data collected from interviews with a total of ten participants. While participating in this study, the risks to you will be minimal, and may include anxiety and worry about revealing negative feelings or opinions about coworkers and supervisors. Participants may also feel a sense of anxiousness when they examine the way that working can get in the way of their academics.

You may also benefit from this study by reflecting on the ways your work enhances your college experience. You may feel a sense of synergy between work and school, and you may come to value your work in new ways. You will also receive a $\$ 5.00$ Starbucks gift card for your participation.

Any information that is obtained in connection with this study and that can be linked to you or identify you will be kept confidential to the degree possible. This information will be kept confidential through the use of pseudonyms. Anecdotes you tell me, however, may identify you to readers if you include specific identifying information. You are encouraged to make your own best decisions about your level of comfort. Additionally, if your employment position makes you privy to student information that would be protected by privacy guidelines, you are encouraged to adhere to those guidelines in our interview.

Your participation is voluntary. You do not have to take part in this study, and it will not affect your position or your relationship with your supervisor. You may also withdraw from this study at any time without affecting your position or your relationship with your supervisor.

If you have questions or concerns about your participation in this study, contact Shannon Timm Watson at shannonw@pdx.edu or 503.725.5652. If you have concerns about your rights as a research subject, please contact Research and Strategic 
Partnerships, Market Center Building $6^{\text {th }}$ floor, Portland State University, (503) 725-4288.

Your signature indicates that you have read and understand the above information and agree to take part in this study, and that you agree to have the interview digitally audio recorded. A copy of this form is available for your own records.

Signature

Print name

Date 


\section{Appendix D: Interview Protocol}

Introduction: Thank you for your participation in this study. In it, I am trying to understand how working on campus may impact undergraduates' student experiences. The interview will consist of a bunch of questions and follow up questions, and will take about an hour. Everything you tell me will be kept in confidence: I will publish your words but will not use your name in my final work. I would like your permission to use your words, and I would like permission to audio record this interview so I can have an accurate record of exactly what you said.

I would like this interview to be very conversational in style. I hope you will feel relaxed and comfortable, and share whatever comes to mind about the topics I bring up. Let's begin with some easy background information.

(Input Area)

- What is your year in school?

- What is your major?

- What is your job title?

- $\quad$ Additional demographics will be listened for in the students' responses throughout the interview.

Next, I'd like to understand your job.

How did you learn about the position, and how were you selected for it?

What are your responsibilities at work?

Prompt: Describe the tasks that you do each day.

Describe your training or orientation program.

Prompt: With whom did you do this? Supervisor, peers, others?

Prompt: What did it cover?

How do know what specific tasks need to be done each day?

Prompt: Who determines it (you or a supervisor)?

Prompt or follow up: Talk about the kinds of decisions you make in this job.

In what way do you perceive yourself contributing to the department or unit in which you work?

Prompt: Make suggestions for future directions or give feedback to supervisors?

How does your job fit in with the university?

Prompt: How does your position affect other students' experiences?

Prompt: What are you able to contribute to the university through this job? 
In your job, who do you communicate with?

Prompts: Other students? Faculty?

Prompt: About what do you communicate?

Prompt: Major field or academics?

Describe your relationship with your coworkers.

Prompt: Interact on the job?

Prompt: Socialize outside work?

Prompt: (if not answered above) What kinds of non-work topics do you discuss?

Prompt: Academics?

Prompt: On- campus activities? Off-campus activities?

What is your relationship with your supervisor like?

Prompt: Support?

Prompt: Feedback?

Prompt: Advice about non-work concerns like academics?

Prompt: Other non- work advice?

I'd like to hear about the parts of your job that are hard or difficult.

Prompt: What parts of it are more difficult than others?

Prompt: What makes these parts difficult?

Prompt: Tell me a story about how you reacted when your job got difficult?

How do you think your job has influenced how you spend your time?

Prompt: What kinds of things do you think you do or don't do because of your job on campus?

Prompt: Campus events?

Prompt: Friends?

Prompt: Organizations or clubs?

Prompt: Events or programs related to your major or academic interest

Prompt for study time.

What do you view as the benefits of working at your job?

What do you view as the drawbacks of working at your job?

Are you enjoying your college experience overall?

Prompt: (if not clear) How has your job affected that feeling? 


\section{Appendix E: Initial Themes}

\begin{tabular}{|c|c|c|}
\hline Broad Category & $\begin{array}{l}\text { Narrower } \\
\text { Category }\end{array}$ & Code \\
\hline Communication & Fac/Staff/Adm/D & Difficult: get pigeonholed by title \\
\hline Communication & Fac/Staff/Adm/D & Work is communication with community members \\
\hline Communication & Fac/Staff/Adm/D & Training: with faculty \\
\hline Communication & Fac/Staff/Adm/D & Networking on campus and at conferences \\
\hline Communication & Fac/Staff/Adm/D & $\begin{array}{l}\text { Work is representing students to donors, faculty and } \\
\text { staff }\end{array}$ \\
\hline Communication & Fac/Staff/Adm/D & Training is networking with administrators \\
\hline Communication & Fac/Staff/Adm/D & Interview was fun (interview was by staff and faculty) \\
\hline Communication & Fac/Staff/Adm/D & Job communicate with staff \\
\hline Communication & Fac/Staff/Adm/D & Difficult: not get taken seriously because he's a student \\
\hline Communication & Fac/Staff/Adm/D & $\begin{array}{l}\text { Difficult: title not indicative of generalist work done } \\
\text { (cred w/ staff) }\end{array}$ \\
\hline Communication & Fac/Staff/Adm/D & communicate w faculty \\
\hline Communication & Fac/Staff/Adm/D & work is communicating with donors \\
\hline Communication & Fac/Staff/Adm/D & participate on all- university committees \\
\hline Communication & Fac/Staff/Adm/D & communication with administrators difficult \\
\hline Communication & Fac/Staff/Adm/D & talk to administrators as equals. \\
\hline Communication & Fac/Staff/Adm/D & administrators look down on students \\
\hline Communication & Fac/Staff/Adm/D & com. w/ admin: I surprised them by being intelligent \\
\hline Communication & Fac/Staff/Adm/D & communication uncomfortable with administrators \\
\hline Communication & Fac/Staff/Adm/D & $\begin{array}{l}\text { Job is to communicate between student committee and } \\
\text { director }\end{array}$ \\
\hline Communication & Fac/Staff/Adm/D & $\begin{array}{l}\text { Work is building connections between students and } \\
\text { administrators }\end{array}$ \\
\hline Communication & Fac/Staff/Adm/D & Talk to fac/staff/ donors about student ife \\
\hline Communication & Fac/Staff/Adm/D & Talk to fac staff donors about psu \\
\hline Communication & Students & $\begin{array}{l}\text { Work is building connections between students and } \\
\text { administrators }\end{array}$ \\
\hline Communication & Students & Group interview was part of selection \\
\hline Communication & Students & Job is bringing people together \\
\hline Communication & Students & job is communicating with students \\
\hline Communication & Students & $\begin{array}{l}\text { Job is addressing needs of client in the moment } \\
\text { (student) }\end{array}$ \\
\hline
\end{tabular}




\begin{tabular}{|c|c|c|}
\hline Communication & Students & $\begin{array}{l}\text { Clients (students) get angry or frustrated at him for not } \\
\text { doing his job correctly }\end{array}$ \\
\hline Communication & Students & benefit of job is helping ppl safe and connected \\
\hline Communication & Students & $\begin{array}{l}\text { Language barrier makes communication difficult } \\
\text { sometimes }\end{array}$ \\
\hline Communication & Students & $\begin{array}{l}\text { Job is to communicate between student committee and } \\
\text { director }\end{array}$ \\
\hline Communication & Students & ownership/ kinship with students (clients) \\
\hline Communication & Students & Job is to create and promote a safe space \\
\hline Communication & Students & Job tasks, support students \\
\hline Communication & Students & job tasks, create visibility \\
\hline Communication & Students & job connect with students of color organizations \\
\hline Communication & Students & $\begin{array}{l}\text { spends more time with friends (students) after getting } \\
\text { this job }\end{array}$ \\
\hline Communication & Students & see friends at work \\
\hline Communication & Students & Relationships not inherent in the work \\
\hline Communication & Peers & difficult working with colleagues $w$ different opinions \\
\hline Communication & Peers & support peers, even through disagreements \\
\hline Communication & Peers & miscommunication with peers really hard \\
\hline Communication & Peers & communication is difficult \\
\hline Communication & Peers & weekly meetings with peers and supervisor \\
\hline Communication & Peers & tricky navigating office dynamics with peers \\
\hline Communication & peers & trained with peers \\
\hline $\begin{array}{l}\text { Peers/ } \\
\text { colleagues }\end{array}$ & leadership & feel supported by peers \\
\hline $\begin{array}{l}\text { Peers/ } \\
\text { colleagues }\end{array}$ & leadership & met someone in the position with qualities he admired \\
\hline $\begin{array}{l}\text { Peers/ } \\
\text { colleagues }\end{array}$ & leadership & contributes to networking for other ambassadors \\
\hline $\begin{array}{l}\text { Peers/ } \\
\text { colleagues }\end{array}$ & leadership & gets feedback from peer employees \\
\hline $\begin{array}{l}\text { Peers/ } \\
\text { colleagues }\end{array}$ & leadership & when not in a leadership role, can be more relaxed \\
\hline $\begin{array}{l}\text { Peers/ } \\
\text { colleagues }\end{array}$ & leadership & trained by peers \\
\hline $\begin{array}{l}\text { Peers/ } \\
\text { colleagues }\end{array}$ & leadership & as a leader, must be mindful of behavior \\
\hline $\begin{array}{l}\text { Peers/ } \\
\text { colleagues }\end{array}$ & leadership & students can't separate work from fun relationships \\
\hline $\begin{array}{l}\text { Peers/ } \\
\text { colleagues }\end{array}$ & leadership & job is directing the work of peers \\
\hline
\end{tabular}




\begin{tabular}{|c|c|c|}
\hline $\begin{array}{l}\text { Peers/ } \\
\text { colleagues }\end{array}$ & leadership & Peers coordinate training for new hires \\
\hline $\begin{array}{l}\text { Peers/ } \\
\text { colleagues }\end{array}$ & Relationship & job is to create relationships with colleagues \\
\hline $\begin{array}{l}\text { Peers/ } \\
\text { colleagues }\end{array}$ & Relationship & communicate with peers, doing social things off campus \\
\hline $\begin{array}{l}\text { Peers/ } \\
\text { colleagues }\end{array}$ & Relationship & focus on boundaries at work \\
\hline $\begin{array}{l}\text { Peers/ } \\
\text { colleagues }\end{array}$ & Relationship & $\begin{array}{l}\text { we socialize outside work have a drink, see a movie, } \\
\text { attend a party }\end{array}$ \\
\hline $\begin{array}{l}\text { Peers/ } \\
\text { colleagues }\end{array}$ & Relationship & $\begin{array}{l}\text { no out of work socializing with peer who is his } \\
\text { roommate too. }\end{array}$ \\
\hline Academics & interference & late to meetings because of class \\
\hline Academics & interference & difficult, lost sleep homeworking all night after working \\
\hline Academics & interference & difficult, giving in necessary in academics and in the job \\
\hline Academics & interference & difficult, grades suffered \\
\hline Academics & interference & $\begin{array}{l}\text { drawback, already had practical experience so school } \\
\text { was waste of time }\end{array}$ \\
\hline Academics & interference & drawback, school got in the way of the job \\
\hline Academics & interference & drawback, job detracted from meaning in classes \\
\hline Academics & interference & difficult, missed class \\
\hline Academics & interference & worked over load, fit academics in when he can \\
\hline Academics & interference & $\begin{array}{l}\text { student leaders do not get academic support like } \\
\text { athletes (study hours, etc.) }\end{array}$ \\
\hline Academics & interference & going to class felt redundant \\
\hline Academics & integrated & work made school feel more important \\
\hline Academics & integrated & got to study at work \\
\hline Academics & integrated & enjoys leisure time to read and think \\
\hline Academics & integrated & communicates with peers about academic topics \\
\hline Academics & integrated & learning on the job was good for my academics \\
\hline Academics & integrated & Enjoys school \\
\hline Academics & integrated & enjoys major \\
\hline Academics & integrated & $\begin{array}{l}\text { enjoys interdisciplinary nature of desease prevention } \\
\text { and intervention }\end{array}$ \\
\hline Academics & integrated & $\begin{array}{l}\text { attends academic events to connect outside his job and } \\
\text { with the community there }\end{array}$ \\
\hline Academics & integrated & attends academic events unrelated to major \\
\hline Academics & integrated & $\begin{array}{l}\text { values academic subjects outside major after being } \\
\text { exposed to them through work }\end{array}$ \\
\hline
\end{tabular}




\begin{tabular}{|c|c|c|}
\hline Involvement & $\begin{array}{l}\text { Campus } \\
\text { activities }\end{array}$ & $\begin{array}{l}\text { Changed friends away from those who did what he did } \\
\text { at work }\end{array}$ \\
\hline Involvement & $\begin{array}{l}\text { Campus } \\
\text { activities }\end{array}$ & job is attending events \\
\hline Involvement & $\begin{array}{l}\text { Campus } \\
\text { activities }\end{array}$ & involvement in clubs increased $\mathrm{w}$ job \\
\hline Involvement & $\begin{array}{l}\text { Campus } \\
\text { activities }\end{array}$ & attempt attending some activities on campus \\
\hline Involvement & $\begin{array}{l}\text { Campus } \\
\text { activities }\end{array}$ & doesn't do things for free, like volunteer \\
\hline Involvement & $\begin{array}{l}\text { Campus } \\
\text { activities }\end{array}$ & so active in job, no energy for other activities \\
\hline Involvement & $\begin{array}{l}\text { Campus } \\
\text { activities }\end{array}$ & job task is planning events \\
\hline Involvement & $\begin{array}{l}\text { Campus } \\
\text { activities }\end{array}$ & feels connected to the university through the job \\
\hline Involvement & $\begin{array}{l}\text { Campus } \\
\text { activities }\end{array}$ & $\begin{array}{l}\text { Off campus activities have more affect on attending on- } \\
\text { campus events than job }\end{array}$ \\
\hline Supervisor & & friendly relationship \\
\hline Supervisor & & feedback weekly informally and each term formally \\
\hline Supervisor & & personal boundaries are protected \\
\hline Supervisor & & relationship is respectful \\
\hline Supervisor & & supervisor recommended me for this role \\
\hline Supervisor & & sup. Helped him realize the value of checking in \\
\hline Supervisor & & supervisor is encouraging \\
\hline Supervisor & & offers suggestions for professional development \\
\hline Supervisor & & walked me through the stages of my development \\
\hline Supervisor & & helped me find what I want to do \\
\hline Supervisor & & helped me navigate change in the department \\
\hline Supervisor & & challenges me professionally \\
\hline Supervisor & & boss is the friend of a friend \\
\hline Supervisor & & is open to communication \\
\hline Supervisor & & I share my aspirations with my boss \\
\hline Supervisor & & checks in with my personal life \\
\hline Supervisor & & is a mentor \\
\hline Supervisor & & gives me a to- do checklist \\
\hline Supervisor & & helps me prioritize \\
\hline Learning & Training & communication \\
\hline Learning & Training & information and resources \\
\hline Learning & Training & situation topics, group problem solving \\
\hline
\end{tabular}




\begin{tabular}{|c|c|c|}
\hline Learning & Training & etiquette \\
\hline Learning & Training & no training at all \\
\hline Learning & Training & learn campus locations \\
\hline Learning & Training & how to give a tour \\
\hline Learning & Training & guidelines \\
\hline Learning & Training & heierarchy \\
\hline Learning & Training & expectations at work \\
\hline Learning & Training & antioppression \\
\hline Learning & Training & organizaing \\
\hline Learning & Training & event planning \\
\hline Learning & Informal & $\begin{array}{l}\text { attends conferences and professional development } \\
\text { events }\end{array}$ \\
\hline Learning & Informal & Networking on campus and at conferences \\
\hline Learning & Informal & learned about student organizations through this job \\
\hline Learning & Informal & communicate to work through a problem \\
\hline Learning & Informal & $\begin{array}{l}\text { communicate about difference of opinion after the } \\
\text { meeting }\end{array}$ \\
\hline Learning & Informal & own my own mistakes \\
\hline Learning & Informal & too much to do, reprioritized \\
\hline Learning & Informal & better at communicating now \\
\hline Learning & Informal & difficult, conference production \\
\hline Learning & Informal & learned to focus on seeking balance \\
\hline Learning & Informal & $\begin{array}{l}\text { mistakes have larger impacts in this job than other areas } \\
\text { of involvement }\end{array}$ \\
\hline Learning & Informal & self directed challenge \\
\hline Learning & Informal & this was my first interview experience \\
\hline Learning & Informal & benefit, Job allows him to engage his brain \\
\hline Learning & Informal & efficiency improved because of this job \\
\hline Learning & Informal & hard to work a full time load \\
\hline Learning & Informal & putting on the conference was "a blur" \\
\hline Learning & Informal & $\begin{array}{l}\text { culturally aligned with not speaking up for himself } \\
\text { (learned new ways of comm) }\end{array}$ \\
\hline Learning & Informal & found a post- college job through this role \\
\hline Learning & Informal & learned to stay calm when people were angry with him \\
\hline Learning & Informal & wants to do similar work after college \\
\hline Learning & Informal & time management improved because of this job \\
\hline I Matter & Decisions & Program creation and evaluation \\
\hline I Matter & Decisions & tweaked job with boss \\
\hline
\end{tabular}




\begin{tabular}{|c|c|c|}
\hline I Matter & Decisions & created a conference \\
\hline I Matter & Decisions & make my own to do lists \\
\hline I Matter & Decisions & built autonomy into the position \\
\hline I Matter & Decisions & created the position with my supervisor \\
\hline I Matter & Decisions & decided how to support peers \\
\hline I Matter & Decisions & create programs that last over time \\
\hline I Matter & Decisions & had the option to work at an information desk \\
\hline I Matter & Decisions & created programs \\
\hline I Matter & Contributions & I bring organization to the team \\
\hline I Matter & Contributions & I bring follow up to the team \\
\hline I Matter & Contributions & I help us focus on the agenda \\
\hline I Matter & Contributions & I help people feel safe and connected \\
\hline I Matter & Contributions & I surprise administrators by being intelligent \\
\hline I Matter & Contributions & I support students in my job \\
\hline I Matter & Contributions & I promote a safe space in my job \\
\hline I Matter & $\begin{array}{l}\text { Kind of a Big } \\
\text { Deal }\end{array}$ & $\begin{array}{l}\text { using personal influence to make things better for } \mathrm{ppl} \text { of } \\
\text { color }\end{array}$ \\
\hline I Matter & $\begin{array}{l}\text { Kind of a Big } \\
\text { Deal }\end{array}$ & $\begin{array}{l}\text { nomination is part of selection, and my superv. } \\
\text { Nominated me }\end{array}$ \\
\hline I Matter & $\begin{array}{l}\text { Kind of a Big } \\
\text { Deal }\end{array}$ & I won a national award \\
\hline I Matter & $\begin{array}{l}\text { Kind of a Big } \\
\text { Deal }\end{array}$ & I like being a focal point in the community. \\
\hline
\end{tabular}

